This item was submitted to Loughborough's Research Repository by the author.

Items in Figshare are protected by copyright, with all rights reserved, unless otherwise indicated.

\title{
Optimized PV-coupled battery systems for combining applications: Impact of battery technology and geography
}

PLEASE CITE THE PUBLISHED VERSION

https://doi.org/10.1016/j.rser.2019.06.003

\section{PUBLISHER}

(c) Elsevier

\section{VERSION}

AM (Accepted Manuscript)

\section{PUBLISHER STATEMENT}

This paper was accepted for publication in the journal Renewable and Sustainable Energy Reviews and the definitive published version is available at https://doi.org/10.1016/j.rser.2019.06.003.

\section{LICENCE}

CC BY-NC-ND 4.0

\section{REPOSITORY RECORD}

Pena-Bello, A., Edward Barbour, Marta Gonzalez, M.K. Patel, and David Parra. 2019. "Optimized Pv-coupled Battery Systems for Combining Applications: Impact of Battery Technology and Geography”. figshare. https://hdl.handle.net/2134/38239. 


\title{
Optimized PV-coupled battery systems for combining applications: impact of battery technology and location
}

\author{
Pena-Bello, A. ${ }^{\mathrm{a}, *}$, Barbour, E. ${ }^{\mathrm{b}, \mathrm{c}}$, Gonzalez, M.C. ${ }^{\mathrm{b}, \mathrm{d}, \mathrm{e}}$, Patel, M.K. ${ }^{\mathrm{a}}$, Parra, D. ${ }^{\mathrm{a}}$ \\ ${ }^{a}$ Energy Efficiency Group, Institute for Environmental Sciences and Forel Institute, University of Geneva, \\ Boulevard Carl-Vogt 66, 1205 Genève, Switzerland. \\ ${ }^{b}$ Department of Civil and Environmental Engineering and Engineering Systems, Massachusetts Institute of \\ Technology, 77 Massachusetts Avenue, 1-290, Cambridge, 02139, United States. \\ ${ }^{c}$ Centre for Renewable Energy Systems Technology, Loughborough University, United Kingdom. \\ ${ }^{d}$ Department of City and Regional Planning, UC Berkeley, 406 Wurster Hall, Berkeley, 94720, United \\ States. \\ e Lawrence Berkeley National Laboratory, Cyclotron Road, Berkeley, 94720, United States.
}

\begin{abstract}
Interest in residential batteries to supply photovoltaic (PV) electricity on demand is increasing, however they are not profitable yet. Combining applications has been suggested as a way to increase their attractiveness, but the extent to which this can be achieved, as well as how the different value propositions may affect the optimal battery technology, remain unclear. In this study, we develop an open-source optimization framework to determine the best-suited battery technology depending on the size and the applications combined, including PV selfconsumption, demand load-shifting, demand peak shaving and avoidance of PV curtailment. Moreover, we evaluate the impact of the annual demand and electricity prices by applying our method to representative dwellings in Geneva, Switzerland and Austin, Texas in the United States. Our results indicate that the combination of applications help batteries to become close to break-even by improving the net present value by up to $66 \%$ when compared with batteries performing PV self-consumption only. Interestingly, we find that the best-suited battery technology in Austin is lithium nickel cobalt aluminum oxide (NCA) as for Geneva lithium nickel manganese cobalt oxide (NMC) batteries reach in average a higher net present value than NCA-based batteries. However, NCA-based batteries could be a more promising alternative in the future.
\end{abstract}

Keywords: PV, energy storage, battery, lithium-ion, electricity demand, combination of applications.

\footnotetext{
*Corresponding author.

Email address: Alejandro.penabello@unige.ch (Pena-Bello, A.)
} 
List of abbreviations.

$\begin{array}{ll}\text { PV } & \text { Photovoltaics } \\ \text { FiT } & \text { Feed-in Tariff } \\ \text { PVSC } & \text { PV self-consumption } \\ \text { PVCT } & \text { Avoidance of PV curtailment } \\ \text { DLS } & \text { Demand load-shifting } \\ \text { DPS } & \text { Demand peak shaving } \\ \text { NMC } & \text { Lithium nickel manganese cobalt oxide } \\ \text { NCA } & \text { Lithium nickel cobalt aluminum oxide } \\ \text { LFP } & \text { Lithium iron phosphate } \\ \text { LTO } & \text { Lithium titanium oxide } \\ \text { ALA } & \text { Advanced lead-acid } \\ \text { VRLA } & \text { Valve-regulated lead-acid } \\ \text { FT } & \text { Flat tariff } \\ \text { DT } & \text { Double tariff } \\ \text { NPV } & \text { Net present value } \\ \text { LCOES } & \text { Levelized cost of energy storage } \\ \text { LVOES } & \text { Levelized value of energy storage } \\ \text { SOC } & \text { State of charge } \\ \text { DoD } & \text { Depth of discharge }\end{array}$

Word Count: 6997 Words

\section{Highlights:}

- Open-source model supporting different battery technologies, generation and demand data.

- NCA and NMC-based batteries are the best-suited for both locations.

- Medium impact of battery technology on PV-coupled battery systems profitability.

- High impact of the combination of applications on PV-coupled battery systems profitability.

- The combination of applications may accelerate the PV-coupled battery systems profitability before 2030 for some battery technologies.

\section{Introduction}

The modularity of solar photovoltaics (PV) is enabling the installation of substantial amounts of generation capacity embedded in the distribution network close to domestic electricity 
demand. In 2016, new installations in the residential sector of the United States (U.S.) represented $67 \%$ of the PV installations with a nominal power lower than $2 \mathrm{MW}$ [1], while in Germany for the same year, new PV installations in the residential sector accounted for $50 \%$ of the total number of installations [2]. This PV development has been facilitated by the rapid decrease in cost of PV modules during the last decade, (e.g. in Germany and the U.S. the price of installed rooftop systems has declined by $60 \%$ and $55 \%$ respectively since 2009) [1, 3]. In parallel with these cost declines, retail electricity prices have risen steadily for the last decade across many countries (e.g. by $78 \%$ in Spain, $52 \%$ in Germany, and $48 \%$ in the U.K. since 2007) [4], while the subsidies for PV electricity fed to the grid, referred to as feed-in tariffs (FiT), have markedly declined (e.g. by $71 \%$ in Germany since 2009) [5]. Additionally, FiT are being restricted, for example, there is a cap on the installed capacity that can profit of the FiT in Australia and Switzerland [6]. Furthermore, the stochastic nature of the solar energy resource prevents PV systems from supplying electricity on demand as is possible with many other conventional technologies such as fossil plants and hydro storage. All of these factors are significantly increasing residential consumers interest in increasing the amount of self-generated PV that they consume in-home (this is referred to as PV self-consumption) by using battery systems [6]. Typical rates of PV self-consumption which ranges between 20 and $40 \%$ for residential consumers can be increased by 13 to $24 \%$ when battery storage is included in the system, using an elementary charging approach [7].

In parallel with this increased consumer interest, battery costs, especially lithium-ion technologies, are following a similar trend as experienced by PV systems and the International Renewable Energy Agency (IRENA) reported a cost reduction of $65 \%$ since 2010 for lithiumion batteries [8]. To encourage battery development, dedicated subsidies have been implemented [9, 10]. In Germany, more than 30000 new residential PV-coupled battery systems have benefited from the federal program since 2013 and in 2017, half of every small PV system was installed with a coupled battery as a result of government economic incentives [10]. Home battery storage is still an emerging market but some projections estimate that households and businesses may account for nearly $60 \%$ of installed storage capacity worldwide by 2040 [11].

Due to its great potential, many authors have investigated key factors impacting on PVcoupled battery systems' profitability. Previous studies have focused on capital and operational expenditures associated with the design [12] and operation [13 16] of PV-coupled battery systems. In addition to cost improvement, the simultaneous provision of various applications has been presented as an alternative strategy to increase the economic attractiveness of energy storage technologies thereby enabling accelerated deployment [17, 18]. The combination of different storage applications has already been investigated at the distribution and transmission networks [17, 19, 20] and for different battery technologies [21]. However, despite the fact that behind-the-meter systems are anticipated to represent major business for stationary storage, previous research on the simultaneous provision of various applications applied to these systems is scant.

The influence of solar resource, demand profiles, jurisdiction and electricity prices across locations has been evaluated for PV self-consumption individually [16, 22]. Other authors 
investigated either various types of applications or geographical dependence and/or using a technology-agnostic approach [12 16, 18, 23 31]. Therefore, various battery technologies available in the market have not been evaluated with the same method and for the full combination of consumer applications.

The main aim of this work is to determine the best-suited battery technology for various combinations of applications. For this, we develop an open-source optimization framework using linear programming to solve the management problem of a PV-coupled battery system. The model is robust and can consider different combinations of applications (e.g. PV self-consumption and demand load shifting), tariff structures, export prices and battery characteristics such as aging, efficiency, lifespan and cycles. Moreover, we evaluate which additional, currently unexploited economic benefit can be reaped by combining applications and compare different battery sizes. Our model can be used by consumers and utility companies to explore different batteries and electricity tariffs for a given demand, PV generation and combination of applications. Importantly, the comparison of our results for Geneva (Switzerland) and Austin (U.S.) allow us to understand whether or not the optimal technology and break-even point for the various combinations of applications is geographically dependent in view of the different pricing structures, annual electricity demand and irradiance of the two locations.

Considering the relevance of these research questions and in order to promote the use of our model by other peers, we also make our model and data open. With this, we contribute towards openness in energy research is lagging behind other fields [32. Open-source energy models permit more meaningful collaboration between academics, are important basis for energy policy and benefit not only academics but the public in general [32, 33. In the interest of transparency, collaboration and science reproducibility in the energy field, this work joins other open-source efforts such as openmod, renewables-ninja [34] and the Linux Foundation Energy.

The remainder of this paper is structured as follows. The materials and methods are presented in the next section. Section 3 gives the optimization results as a function of the combination of applications, battery technology and geography. Section 4 presents the implications of our results and finally the main conclusions are presented.

\section{Material and methods}

Fig. 1 is a schematic representation of our method. In first place, we specify the input data for electricity demand and PV generation (Section 2.1). The applications and their combinations are subsequently defined along with the respective electricity tariff structure (Section 2.2). Then, the battery technologies, system topology, components and techno-economic indicators are presented (Sections 2.3, 2.4 and 2.5). Finally, the schedule optimization is described (Section 2.6). Across the study we use USD as common currency for both locations 1

\footnotetext{
${ }^{1}$ Exchange rates used: $1 \mathrm{USD} / \mathrm{CHF}$ and $1.18 \mathrm{USD} / \mathrm{EUR}$.
} 


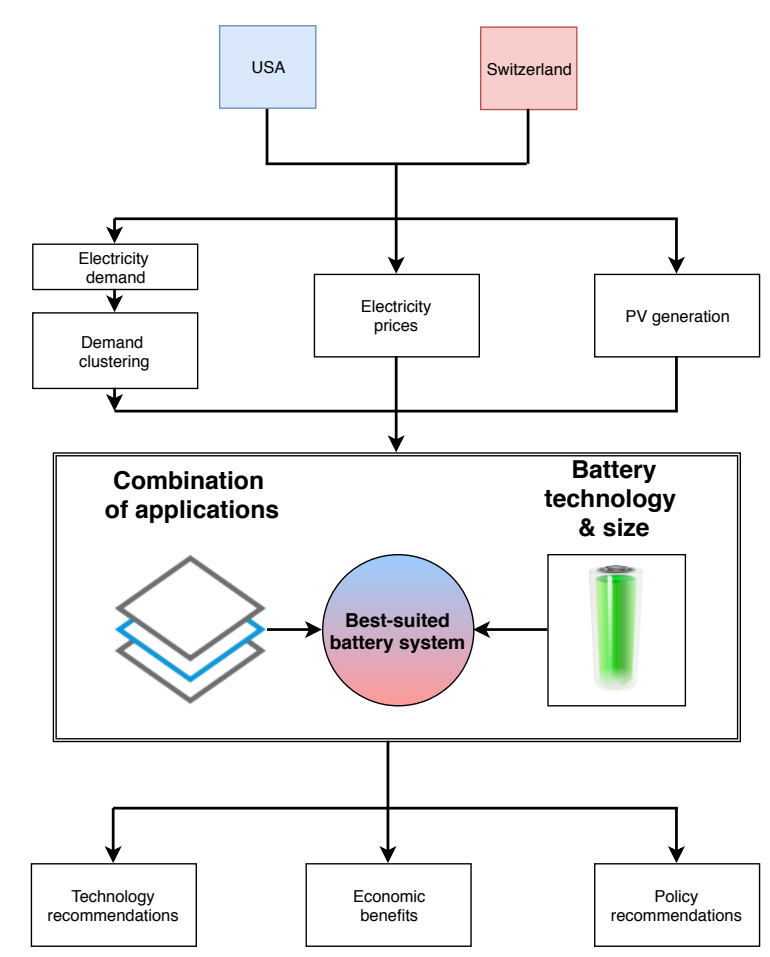

Fig. 1: Schematic representation of the modeling approach proposed.

\subsection{Demand and PV generation}

We use electricity consumption data with 15-minute temporal resolution monitored in single dwellings in Western Switzerland (636 dwellings) and Austin, Texas (308 dwellings) during the year 2015. Considering this amount of data, we opt to form representative consumer groups in order to reduce the computational time required. To generate these representative consumer groups, we employ clustering to produce groups of consumers with similar behaviors. We split the consumers according to their annual consumption into three separate groups, i.e. a low, medium and high consumption group in both locations. Finally, within these three groups we cluster based on the average daily load profile. We opt to produce four clusters in each consumption bracket, noting that selecting the number of clusters in highly dimensional data is a difficult task. From each cluster we select the household that is closer to the centroid which is subsequently optimized. The results presented in this study are the average of the four representative households of each cluster per consumption bracket. For further information see Section 1.1 of Supplementary Information (SI).

Environmental variables including outdoor temperature and horizontal solar irradiance monitored across both locations are used to model PV generation. We focus on the median PV size of the empirical distribution across Switzerland (i.e. $4.8 k W_{p}$ ) [35] and Texas (i.e. $5 k W_{p}$ ) [36] for our baseline results (i.e. unchanged PV size), while alternative scenarios including the 25th (i.e. 3.2 and $3.15 k W_{p}$ for Geneva and Austin respectively) and 75th percentiles (i.e. 6.9 and $6.4 k W_{p}$ for Geneva and Austin respectively) are shown in Section 4 of the Supplementary Information. 


\subsection{Electricity tariff and battery applications}

The operation of a residential battery as well as the number of applications it can deliver depends on the tariff structure. Since there is not a market mechanism incentivizing the export of electricity from residential batteries to the main grid, this case is not considered either.

Electricity prices used in this study are based on available tariffs which are offered by the local utility companies in the two locations. Both, single tariffs and double tariffs (also called Time-of-Use tariffs, which have a peak and off-peak periods) are considered in the analysis. In Geneva, double tariffs are applied all-year-round, while in Austin, they are applied only in summertime. The export price is assumed to be the wholesale electricity price as is the case for traditional electricity generators. This is already the case in Switzerland for installations which are on the waiting list to be granted a one-off subsidy for the capital investment in PV [6] and this is expected to become a widespread policy as a consequence of falling cost of PV technology. We use 2015 wholesale electricity prices from the Electric Reliability Council of Texas day-ahead market (ERCOT southern load zone) and from the European Power Exchange day-ahead market for Switzerland (EPEXSPOT). It is important to note that, apart from the electricity price, electricity bills include other fixed costs as well, such as taxes and grid usage.

Capacity tariffs, which bill the peak electricity demand (i.e. in USD $/ \mathrm{kW}$ ) during a billing period, have been widely applied for large consumers, typically belonging to the secondary and tertiary economic sectors. For residential customers capacity tariffs have only being marginally applied (e.g. by the Arizona Public Services in the U.S.), although their implementation is being suggested following the penetration of air conditioning, heat pumps and electric vehicles [37]. As a first attempt to include them we assume low capacity tariffs applied to large consumers by the local utilities in the two locations (i.e. around 10 $\mathrm{USD} / \mathrm{kW} /$ month), taking a more conservative approach than other studies (e.g. see [31]). In order to ensure that the tariffs are revenue neutral in average for all the households evaluated (i.e. the consumer bill remains similar), the per-kWh rates are reduced by $20 \%$ in Geneva and $30 \%$ in Austin whenever the capacity tariff is used. Finally, following the example in Germany, a (physical) feed-in limit of $50 \%$ of the nameplate PV-system capacity for both countries is assumed as a preventive measure to keep the power system stable during periods of high PV production [12]. Table 1 provides the input data for every battery application depending on the tariff structure.

On-grid batteries can perform up to 15 applications depending on the discharge duration, scale and stakeholder [38]. Consumer applications refer to those which help consumer to minimize the electricity bill, with the number of relevant applications depending on the bill structure. Considering the various components of a household electricity bill, a residential battery can perform the following applications (see Fig. 2):

PV self-consumption (PVSC): PV surplus electricity is stored in a battery and used later on to meet local demand when it is higher than PV generation (see Fig. 2 a.). The main driver is the price difference between the electricity imported from the grid (i.e. retail price) 
Table 1: Various electricity tariffs components depending on the bill structure and for the two locations used in this study to test various battery applications.

\begin{tabular}{|c|c|c|c|c|c|}
\hline \multicolumn{2}{|c|}{ Name } & Units & Austin & Geneva & Based on \\
\hline \multicolumn{2}{|c|}{ Flat Tariff } & $\mathrm{USD} / \mathrm{kWh}$ & 0.073 & 0.22 & Energy \\
\hline \multirow{2}{*}{ Double Tariff ${ }^{a}$} & On-peak ${ }^{\mathrm{b}}$ & $\mathrm{USD} / \mathrm{kWh}$ & 0.183 & 0.24 & Energy \\
\hline & Off-peak & $\mathrm{USD} / \mathrm{kWh}$ & 0.056 & 0.152 & Energy \\
\hline \multicolumn{2}{|c|}{ Export price } & $\mathrm{USD} / \mathrm{kWh}$ & $0.027^{\mathrm{c}}$ & $0.047^{\mathrm{b}}$ & Energy \\
\hline \multicolumn{2}{|c|}{ Capacity tariff } & $\mathrm{USD} / \mathrm{kW} /$ month & 10.14 & 9.39 & Power \\
\hline \multicolumn{2}{|c|}{ Feed-in limit } & $\% k W_{p-P V}$ & $50 \%$ & $50 \%$ & Regulation \\
\hline
\end{tabular}

${ }^{a}$ When the capacity tariff is applied, the Double tariff is reduced by $20 \%$ in Geneva and 30\% in Austin.

${ }^{\mathrm{b}}$ In the U.S. on-peak time is only from June to September from 1 p.m. to 7 p.m. on weekdays. In Switzerland, on-peak time is all year-round from 7 a.m. to 10 p.m. on weekdays and from 5 p.m. to 10 p.m. on weekends.

${ }^{c}$ We use real hourly wholesale price for ERCOT and EPEXSPOT markets. The price shown in the table is the average wholesale price.

and the electricity exported to the grid (i.e. FiT or wholesale price as in this study).

Avoidance of PV curtailment (PVCT): In some regions with substantial PV penetration, a feed-in limit is set above which PV power cannot be injected to the grid to keep grid stability (see Fig. 2 b.). Electricity dissipation is typically done using the PV inverter [12]. Batteries can prevent this PV curtailment by storing this electricity and meeting local demand later on. The implementation of PV curtailment is determined by regulation.

Demand load-shifting (DLS): A battery is used to exploit varying tariff differentials (see Fig. 2 c.). The battery charges from the grid when prices are low (off-peak periods) and it discharges when they are high (peak periods). The existence of varying-price tariffs is a prerequisite for demand load-shifting.

Demand peak-shaving (DPS): The discharge of a battery is used to reduce the maximum power drained from the grid (in $\mathrm{kW}$ ) used during a specified period. Demand-peak shaving can be used to mitigate demand electricity peaks which can result in distribution network upgrading as well as expensive electricity supply (see Fig. 2 d.). The main driver is therefore the presence of a capacity-based component in the electricity tariff.

Back-up power is excluded from this study since we focus on distribution areas with a high level of grid stability (for both utilities referred in this study, the number of minutes of power failure experienced by a typical customer in a year was below 100 minutes in 2016) [39]. However, we acknowledge that in some locations back-up power is the main motivation for battery installation (e.g. Hawaii).

\subsection{Battery technologies}

Battery technologies widely differ in cost, aging, lifetime and round trip efficiency [38], and we compare here six representative products of different technologies within both the lithium and 

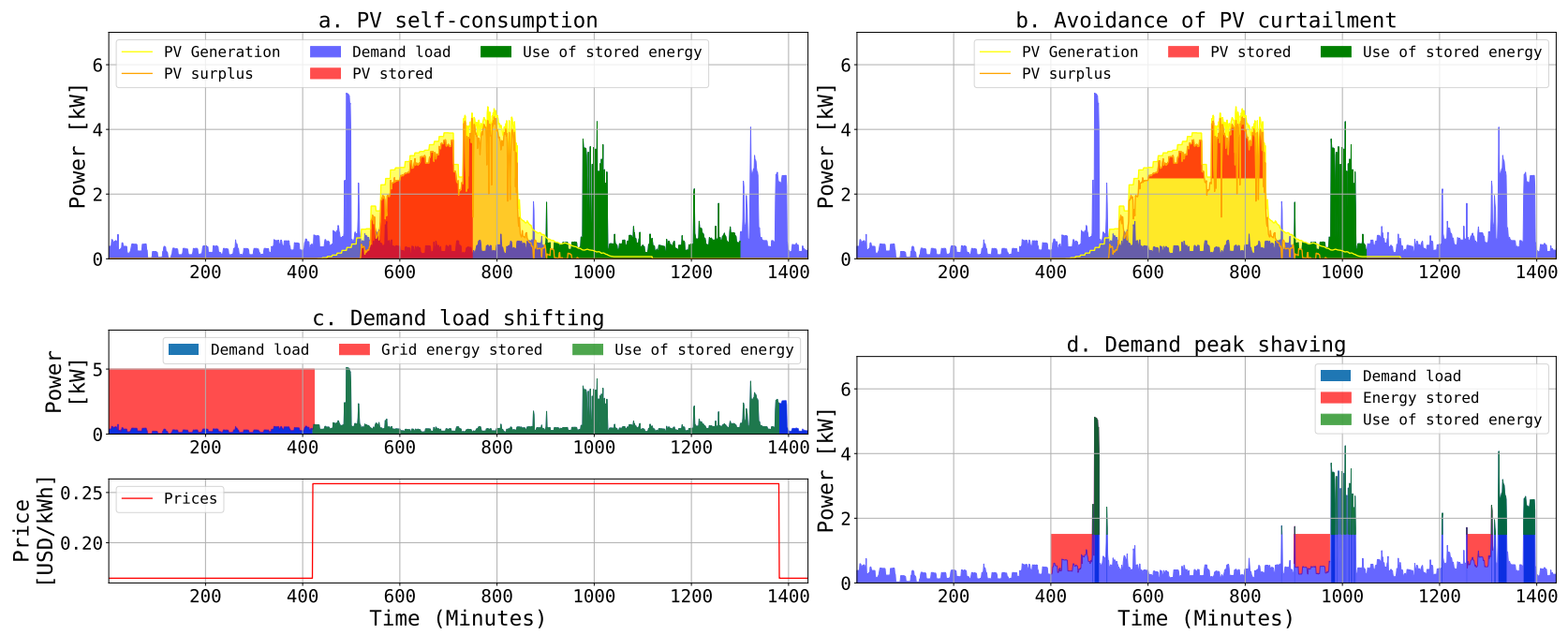

Fig. 2: Schematic representation of the four applications analyzed in this study. a. PV self-consumption, b. Avoidance of PV curtailment, c. Demand load shifting and d. Demand peak shaving. This figure is explanatory and does not fully represent the model constraints or approach, which are suitably explained in the Section 2.6 .

Table 2: Battery specifications for the six technologies compared in this study. SOC denotes the state of charge.

\begin{tabular}{|c|c|c|c|c|c|c|c|c|c|c|c|}
\hline Technology & $\begin{array}{l}\text { Cathode } \\
\text { Material }\end{array}$ & $\begin{array}{l}\text { Cycles } \\
\text { @ DoD }\end{array}$ & $\begin{array}{l}\text { Maximum } \\
\text { lifetime } \\
\text { [years] }\end{array}$ & $\begin{array}{l}\text { Roundtrip } \\
\text { Efficiency }\end{array}$ & $\begin{array}{c}\text { Energy Costs } \\
{[\text { USD/nominal kWh] }}\end{array}$ & $\begin{array}{l}\text { Maximum charge/ } \\
\text { discharge rate }[\mathrm{kW}]\end{array}$ & $\triangle \mathrm{SOC}$ & $\begin{array}{l}\text { Maximum } \\
\text { SOC }\end{array}$ & $\begin{array}{l}\text { Minimum } \\
\text { SOC }\end{array}$ & $\begin{array}{l}\text { Cycle \& calendar } \\
\text { aging factor per year }\end{array}$ & Reference \\
\hline \multirow[t]{3}{*}{ Li-ion } & NMC & $5000 @ 100 \%$ & 15 & $91.8 \%$ & 410 & $0.4^{*} \mathrm{C}$ & 1 & 1 & 0 & $0.059 \& 0.07$ & $41-43$ \\
\hline & LFP & $6000 @ 100 \%$ & 20 & $94 \%$ & 980 & $2^{*} \mathrm{C}$ & 1 & 1 & 0 & $0.024 \& 0.05$ & $41,42,45$ \\
\hline & LTO & $15000 @ 100 \%$ & 25 & $96.7 \%$ & 1630 & $4^{*} \mathrm{C}$ & 1 & 1 & 0 & $0.003 \& 0.04$ & $\begin{array}{l}\text { 46, personal } \\
\text { communication }\end{array}$ \\
\hline Lead-acid & ALA & $4500 @ 70 \%$ & 15 & $91 \%$ & 750 & $1 * \mathrm{C}$ & 0.7 & 0.9 & 0.2 & $0.06 \& 0.07$ & $41,42,48$ \\
\hline
\end{tabular}

a The cycle aging factor is given for a $50 \%$ depth-of-discharge. For further information please refer to the section 2 of the supplementary information.

lead-acid families. Within lithium-ion technologies, we include the most common technologies in grid applications, namely lithium nickel manganese cobalt oxide (NMC) and lithium iron phosphate (LFP). Additionally, we include lithium nickel cobalt aluminum oxide (NCA) which have relative competitive installation costs, and lithium titanium oxide (LTO) that is the more thermally stable technology and has extremely high cycle lifetime [8]. As for leadacid we include traditional valve-regulated lead-acid (VRLA) and advanced lead-acid (ALA). The latter incorporates an ultra-capacitor into a conventional lead-acid cell, increasing efficiency and cycle life. Advanced lead-acid batteries are currently in the demonstration phase and hence costs are currently higher than for conventional lead-acid batteries. The selected representative products are compared with the most likely values found in the market according to Schmidt et al. [40] (the values are presented in the Section 1.5 of the Supplementary Information).

The technical and economic battery input data required by the model were collected from 
Table 3: Values selected for the technical and economic assessment of PV-coupled battery systems.

\begin{tabular}{lccc}
\hline Component & Units & Value & Reference \\
\hline Charge controller efficiency & $\%$ & 98 & $50]$ \\
Inverter efficiency & $\%$ & 94 & {$[50]$} \\
Bi-directional inverter cost & {$[\mathrm{USD} / \mathrm{kW}]$} & 600 \\
Bi-directional inverter lifetime & years & 15
\end{tabular}

publicly available data-sheets and personal communication with representative manufacturers. Table 2 presents the key specifications for the six battery technologies defined by the type of cathode material. Other relevant values for the techno-economic assessment of PVcoupled battery systems, such as the inverter and converter efficiencies, discount rate and costs are given in Table 3 . Three currently available battery sizes were assessed, small (3 $\mathrm{kWh})$, medium $(7 \mathrm{kWh})$ and large $(14 \mathrm{kWh})$. Moreover, battery aging is modeled on a daily basis for the first year using the maximum among the daily calendar factor and the daily cyclic factor. The former is calculated as the multiplicative inverse of the calendar lifetime, whereas the cyclic aging factors are based on Woehler curves $2^{2}$ for every technology. The cyclic aging is then given by the number of cycles per day at the given depth of discharge (depth-of-discharge), divided by the maximum number of cycles at a given depth-of-discharge [49]. Further details and a detailed example are presented in Section 2 of the Supplementary Information.

\subsection{PV-coupled battery system}

This study focuses on the combined investment in a PV-coupled battery system; more specifically, we analyze the techno-economic implications of adding a battery system when purchasing a new PV system that would otherwise be installed on its own. We consider a DC-coupled topology (i.e., coupled on the direct current side) since a lower investment is required and the overall efficiency of stored PV electricity is higher than in AC-coupled topologies (i.e., coupled on the alternating current side) [51]. Moreover, the prevention of PV curtailment is possible (for further information see Section 1.4 of supplementary information). Since manufacturers claim no operational costs required for residential PV and battery technologies, we

\footnotetext{
${ }^{2}$ The Woehler curves show the number of remaining cycles of a battery as a function of depth of discharge until the end of lifetime. This curve is given by some battery manufacturers in data sheets.
} 
set them to zero [43, 47]. Installation costs are considered for the inverter and battery and are assumed to be high for both countries (i.e. USD 2000).

\subsection{Techno-economic indicators}

Three complimentary indicators are used to analyze the techno-economic performance of batteries coupled with PV systems, i.e. the PV system is excluded in the analysis since we are interested in the decision of adding a battery. The levelized cost of energy storage, LCOES (USD/kWh) quantifies the cost associated with the total electricity supplied by the battery throughout the life of the system (see Eq. 1). The second indicator is the levelized value of energy storage, LVOES (USD $/ \mathrm{kWh}$ ). It quantifies the revenue associated with the battery discharge throughout the life of the system (see Eqs. 2 and 3). Finally, the net present value (NPV) calculated as the sum of the discounted cash flows over the lifetime of the battery system (Eq. 4) is used to appraise the overall impact of the system configuration

and operation for each combination (geography, technology, consumer type and combination of applications) on the economic profitability of residential batteries.

$$
\begin{gathered}
L C O E S=\frac{\sum_{i=0}^{N} \frac{C A P E X}{(1+r)^{i}}+\sum_{i=1}^{N} \frac{O P E X}{(1+r)^{i}}}{\sum_{i=1}^{N} \frac{E_{\text {dis }}}{(1+r)^{i}}} \\
\text { LVOES }=\frac{\sum_{i=1}^{N} \frac{C F_{\text {Batt }_{i}}}{(1+r)^{i}}}{\sum_{i=1}^{N} \frac{E_{\text {dis }}}{(1+r)^{i}}} \\
C F_{\text {Batt }_{i}}=C F_{P V-B_{\text {Batt }}}-C F_{P V_{i}} \\
N P V=\sum_{i=1}^{N} \frac{C F_{\text {Batt }_{i}}}{(1+r)^{i}}-\sum_{i=0}^{N} \frac{C A P E X}{(1+r)^{i}}
\end{gathered}
$$

Where CAPEX are the capital expenditures (in USD), OPEX are the operational expenditures (in USD), $r$ is the discount factor, $E_{d i s}$ is the energy discharged from the battery and $\mathrm{N}$ is the lifetime of the project (i.e., the same as the inverter which in this study is considered to be 15 years). The cash flows of the PV-coupled battery system are represented as $C F_{P V-B a t t}$, $C F_{\text {Batt }}$ are the cash flows due to the battery only, and $C F_{P V}$ are the cash flows due to the PV system.

\subsection{Optimization of the battery schedule}

The management problem of a PV-coupled battery system is solved by Mixed Integer Linear Programming, using Pyomo, an open-source tool for modeling optimization applications in Python [55] and solved with CPLEX. The battery schedule is optimized for every day (i.e. $24 \mathrm{~h}$ optimization framework) and we assume perfect day-ahead forecast of the electricity demand load, solar PV generation and wholesale prices in order to determine the maximum economic potential regardless of the forecast strategy used. Battery aging was treated as an 
exogenous parameter, calculated on daily basis and was not subject to optimization (for further information we invite the reader to see section 2 of the Supplementary Information). The temporal resolution of the input data and simulation is 15 minutes, with this value providing a reasonable compromise between the modeling real performance and computational speed [56]. The model objective function have two components, namely the energy and power components of the electricity bill. As the tariff structure depends on the applications considered, a boolean parameter activates the power-based factor of the bill when is necessary.

Every optimization was run for one year and then the results are linearly-extrapolated to reach the battery end of life. We assume $30 \%$ of capacity depletion as the end of life [53] and when the battery lifetime exceeds the inverter lifetime, the residual value of the battery is considered using straight-line depreciation [57]. Replacement is considered when the battery cannot match the inverter lifetime which is taken as the project lifetime, we take a conservative approach maintaining the same cost in the future discounted to the present, due to the high uncertainty linked to future battery costs for different battery technologies. The analysis is done with same electricity prices for all years across battery lifetime. The model objective function, constraints, variables and parameters are presented below. The validation of the model can be found in Section 3 of the Supplementary Information. The model and the U.S. data (the Swiss data is confidential) are publicly available in https://github.com/ alefunxo/Basopra.

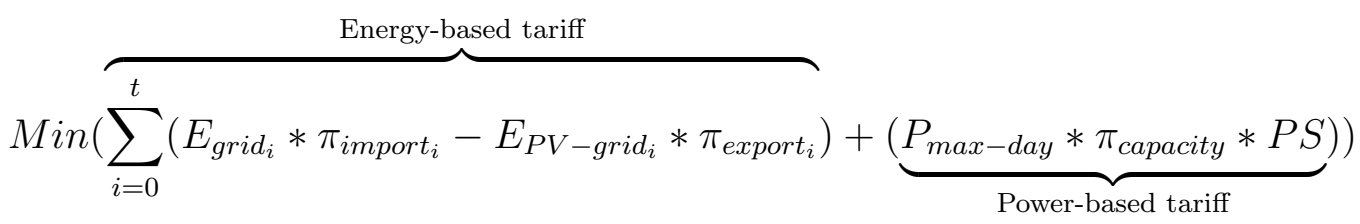

Where the energy-based tariff is given by $E_{\text {grid }_{i}}$ which is the electricity drawn from the grid, $\pi_{\text {import }_{i}}$ is the import price (i.e., retail price), $E_{P V-\text { grid }_{i}}$ is the PV-electricity exported to the grid, $\pi_{\text {export }}$ is the export price (i.e., the wholesale price in this study), all these variables have the sub-index $i$ representing every time step from 0 to $t$ (i.e., 15-minutes step for this study). As for the power-based tariff, it is given by $P_{\max -d a y}$, which is the maximum power required from the grid for the day, $\pi_{\text {capacity }}$ which is the capacity tariff (i.e., in USD $/ \mathrm{kW} /$ day) and $P S$ is a boolean variable which indicate the use of demand peak shaving in the combination of applications. The objective function is subject to the constraints introduced below.

Subject to:

Battery constraints:

$$
\begin{gathered}
S O C_{\min } \leq S O C_{i} \leq S O C_{\max } \\
E_{\text {char }_{i}}=E_{P V-\text { batt }_{i}}+E_{\text {grid-batt }_{i}} \\
E_{\text {dis }_{i}} \leq\left(S O C_{i-1}-S O C_{\text {min }}\right) * C_{\text {batt }}^{\text {nom }}
\end{gathered}
$$


Where, $S O C_{\min }$ and $S O C_{\max }$ are the minimum and maximum states of charge and $S O C_{i}$ is the state of charge at the instant $i$, below and above which the battery is never discharged and charged. $E_{\text {char }_{i}}$ the energy charged into the battery, $E_{P V-b a t t_{i}}$ is the PV energy flow to the battery and $E_{\text {grid-batt }_{i}}$ is the grid energy flow to the battery. $E_{\text {dis }}$ is the electricity discharged from the battery and $C_{b a t t}^{\text {nom }}$ is the nominal capacity of the battery.

Energy balance constraints:

$$
\begin{aligned}
& E_{\text {grid }_{i}}=E_{\text {grid-load }_{i}}+E_{\text {grid-batt }_{i}}+E_{\text {loss-inv-grid }_{i}} \\
& E_{P V_{i}}=E_{P V-\text { load }_{i}}+E_{P V-\text { batt }_{i}}+E_{P V-\text { grid }_{i}}+E_{P V-\text { curt }_{i}}+E_{\text {loss-conv }_{i}}+E_{\text {loss-inv-PVi }} \\
& E_{\text {load }_{i}}=E_{P V-\text { load }_{i}}+E_{\text {grid-load }_{i}}+E_{\text {dis }_{i}} * \eta_{\text {inv }} \\
& S O C_{i}=\frac{\left(S O C_{i-1} * C_{\text {batt }^{\text {nom }}}+E_{\text {char }_{i}}-E_{\text {dis }_{i}}-E_{\text {loss-batt }_{i}}\right)}{C_{\text {batt }}^{\text {nom }}} \\
& E_{d i s_{i}}=E_{\text {batt-load }_{i}}+E_{\text {loss-inv-batt }_{i}}
\end{aligned}
$$

Energy balance constraints verify that all the energy flows sum up to the total energy provided by the grid $\left(E_{\text {grid }_{i}}\right)$, the PV system $\left(E_{P V_{i}}\right)$ and to cover the household demand $\left(E_{\text {load }_{i}}\right)$, as well as to define the state of charge and the energy discharged from the battery. The energy flows are represented using the convention $E_{\text {from-to }}$, for instance, $E_{P V-\text { grid }}$ is the energy from the PV system injected into the grid. The losses are represented using the convention $E_{\text {loss-device-dueto }}$, for instance, $E_{\text {loss-inv-PV }}$ represents the losses in the inverter due to PV electricity flows. The efficiencies are represented using the convention $\eta_{\text {device }}$, where the device can be the converter $\left(\eta_{\text {conv }}\right)$, the inverter $\left(\eta_{\text {inv }}\right)$ or the battery $\left(\eta_{\text {batt }}\right)$.

Efficiency losses constraints:

$$
\begin{gathered}
E_{\text {loss-conv }_{i}}=\left(E_{P V-\text { load }_{i}}+E_{P V-\text { batt }_{i}}+E_{P V-\text { grid }_{i}}+E_{\text {loss-inv }-P V_{i}}\right) *\left(1-\eta_{\text {conv }}\right) \\
E_{\text {loss-biinv }_{i}}=E_{\text {loss-inv-PV }_{i}}+E_{\text {loss-inv-grid }_{i}}+E_{\text {loss-inv-batt }_{i}} \\
E_{\text {loss-inv-PVi }_{i}}=\left(E_{P V-\text { load }_{i}}+E_{P V-\text { grid }_{i}}\right) *\left(1-\eta_{\text {inv }}\right) / \eta_{\text {inv }} \\
E_{\text {loss-inv-grid }_{i}}=E_{\text {grid-batt }_{i}} *\left(1-\eta_{\text {inv }}\right) / \eta_{\text {inv }} \\
E_{\text {loss-inv-batt }_{i}}=E_{\text {dis }_{i}} *\left(1-\eta_{\text {inv }}\right) \\
E_{\text {loss-batt }_{i}}=E_{\text {char }_{i}} *\left(1-\eta_{\text {batt }}\right)
\end{gathered}
$$

Efficiency losses constraints account for the losses of the converter (Eq. 14), of all the losses in the inverter (Eq. 15), of the losses in the inverter due only to the PV (Eq. 16), of the losses in the inverter due to grid charging (Eq. 17), of the losses in the inverter due to the energy discharged from the battery (Eq. 18), and the losses in the battery (Eq. 19). Energy flows are, for convention, considered after the inverter, to calculate the converter losses, the inverter efficiency has to be considered (see Fig. 7 of the Supplementary Information). The PV curtailed is not taken into account as losses and it is assumed to be curtailed at the converter. 
Power constraints:

$$
\begin{gathered}
P_{\text {char }_{i}} \leq P_{\text {max-char }} \\
P_{\text {dis }_{i}} \leq P_{\text {max-dis }} \\
P_{P V_{i}} \leq P_{\text {conv }} \\
P_{P V-\text { grid }_{i}}+P_{P V-\text { load }_{i}}+P_{\text {dis }_{i}}+P_{\text {loss-inv-PV }}+P_{\text {loss-inv-batt }_{i}} \leq P_{\text {inv }} \\
P_{\text {grid-batt }_{i}}+P_{\text {loss-inv-grid }} \leq \\
\text { inv }
\end{gathered}
$$

Power variables are designated using $\mathrm{P}$ and follow the same conventions previously presented. The battery maximum charging and discharging power are represented by $P_{\max -c h a r}$ and $P_{\text {max-dis. }} . P_{\text {conv }}$ and $P_{i n v}$ represent the converter and inverter rating.

Application selection:

$$
\begin{gathered}
P_{P V-\text { grid }_{i}} \leq P_{\text {limit }} \quad \forall \quad i \quad \text { if } \quad P V C T=1 \\
E_{\text {grid-batt }_{i}}=0 \quad \forall \quad i \quad \text { if } \quad D L S=0 \\
P_{\text {grid }_{i}} \leq P_{\text {max-day }} \quad \forall \quad \text { i if } \quad D P S=1
\end{gathered}
$$

Since the model allows to select from a pool of applications (i.e., PV self-consumption, avoidance of PV curtailment, demand load shifting and demand peak shaving), when one of the applications is selected the corresponding constraint is applied (except for PVSC which is applied by default and includes all the constraints mentioned above). Thus, when PVCT is selected, a constraint to the power feed-in $P_{P V-g r i d}$ is applied (Eq. 25), when demand load shifting is not applied (i.e., DLS=0), the battery cannot charge from the grid. Finally, when demand peak shaving is applied (i.e., DPS=1), a constraint on the maximum power drawn from the grid $P_{\text {gridi }}$ is applied (Eq. 27) and limited to the minimum possible power $\left(P_{\max -d a y}\right)$, which is a result from the optimization.

\section{Results}

Since we aim to determine the best-suited battery technology for various combination of applications and analyze the impact of geography and size, we present first the results for a typical battery size of $7 \mathrm{kWh}$ depending on the battery technology, location and for different combinations of applications and tariff structures (see Table 5). PV self-consumption is common across all combinations since this application is the baseline for residential batteries. Depending on the combination of applications, different tariff structures are needed, thus combinations of tariffs are done (e.g if demand peak shaving is combined with PV selfconsumption, then a combination of flat tariff with capacity tariff is made - combination 2 in Table 5). Afterward, we evaluate the impact of the battery size. All results are based on a representative (median of the distribution) fixed PV size in each geographical region $(4.8 \mathrm{~kW}$ for Geneva and $5 k W_{p}$ for Austin). Results for other PV sizes and alternative combinations of applications are given in Sections 4 and 5 of the Supplementary Information. 
Table 4: List of model parameters and variables.

\begin{tabular}{|c|c|c|c|c|c|}
\hline Modeling parameters & Name & Units & Modeling variables & Name & Units \\
\hline Converter efficiency & $\eta_{\text {conv }}$ & $\%$ & PV generation fed to the load & $E_{P V-l o a d}$ & $\mathrm{kWh}$ \\
\hline Inverter efficiency & $\eta_{\text {inv }}$ & $\%$ & PV generation exported to the grid & $E_{P V-\text { grid }}$ & $\mathrm{kWh}$ \\
\hline Inverter rating & $P_{i n v}$ & $\mathrm{~kW}$ & PV generation injected to the battery & $E_{P V-b a t t}$ & $\mathrm{kWh}$ \\
\hline Battery Efficiency & $\eta_{\text {batt }}$ & $\%$ & PV generation curtailed & $E_{P V-c u r t}$ & $\mathrm{kWh}$ \\
\hline Maximum discharge power & $P_{\text {max-dis }}$ & $\mathrm{kW}$ & Energy lost due to converter efficiency & $E_{\text {loss-conv }}$ & $\mathrm{kWh}$ \\
\hline Maximum charge power & $P_{\text {max-char }}$ & $\mathrm{kW}$ & $\begin{array}{l}\text { Total energy lost due to bi-directional } \\
\text { inverter efficiency }\end{array}$ & $E_{l o s s-b i n v}$ & $\mathrm{kWh}$ \\
\hline Battery nominal capacity & $C_{\text {batt }}^{\text {nom }}$ & $\mathrm{kWh}$ & $\begin{array}{l}\text { PV energy lost due to bi-directional } \\
\text { inverter efficiency }\end{array}$ & $E_{\text {loss-PVinv }}$ & $\mathrm{kWh}$ \\
\hline Battery lifetime & $\mathrm{N}$ & years & $\begin{array}{l}\text { Grid energy lost due to bi-directional } \\
\text { inverter efficiency }\end{array}$ & $E_{\text {loss-gridinv }}$ & $\mathrm{kWh}$ \\
\hline Battery maximum state of charge & $S O C_{\max }$ & $\%$ & $\begin{array}{l}\text { Battery energy lost due to bi-directional } \\
\text { inverter efficiency }\end{array}$ & $E_{l o s s-b a t t i n v}$ & $\mathrm{kWh}$ \\
\hline Battery minimum state of charge & $S O C_{\min }$ & $\%$ & Energy lost due to battery efficiency & $E_{\text {loss-batt }}$ & $\mathrm{kWh}$ \\
\hline Retail prices & $\pi_{\text {import }}$ & $\mathrm{USD} / \mathrm{kWh}$ & Energy drained from the battery & $E_{d i s}$ & $\mathrm{kWh}$ \\
\hline Export prices & $\pi_{\text {export }}$ & $\mathrm{USD} / \mathrm{kWh}$ & Energy injected to the battery & $E_{\text {char }}$ & $\mathrm{kWh}$ \\
\hline Capacity tariff & $\pi_{\text {capacity }}$ & $\mathrm{USD} / \mathrm{kW}$ & Energy delivered from the battery to the load & $E_{\text {batt-load }}$ & $\mathrm{kWh}$ \\
\hline Feed-in limit & $P_{\text {limit }}$ & $\%$ & Energy imported from the grid to the battery & $E_{\text {grid-batt }}$ & $\mathrm{kWh}$ \\
\hline Combination of applications & [PVCT, PVSC, DLS, DPS] & Boolean array & Energy imported from the grid to the load & $E_{\text {grid-load }}$ & $\mathrm{kWh}$ \\
\hline Load demand & $E_{\text {load }}$ & $\mathrm{kWh}$ & Energy drained from the grid & $E_{\text {grid }}$ & $\mathrm{kWh}$ \\
\hline PV generation & $E_{P V}$ & $\mathrm{kWh}$ & Maximum power drained from the grid & $P_{\text {max-day }}$ & $\mathrm{kW}$ \\
\hline Optimization time framework & $\mathrm{t}$ & minutes & Power related to any energy parameter & $P_{x}=E_{x} / \Delta t$ & $\mathrm{~kW}$ \\
\hline Temporal resolution & $\Delta t$ & fraction of hour & State of charge & $S O C_{i}$ & $\%$ \\
\hline
\end{tabular}

Table 5: Various combination of applications and the respective electricity tariff structure compared in this study. If the application indicator is ON, it means that the referred application is included in the combination, same is valid for the electricity tariff structure indicators.

\begin{tabular}{|c|c|c|c|c|c|c|c|c|}
\hline \multirow{2}{*}{ Combination name } & \multicolumn{4}{|c|}{ Applications } & \multicolumn{4}{|c|}{ Electricity tariff structure } \\
\hline & $\begin{array}{l}\text { PV Self- } \\
\text { consumption } \\
\text { (PVSC) }\end{array}$ & $\begin{array}{c}\text { Avoidance of } \\
\text { PV curtailment } \\
\text { (PVCT) }\end{array}$ & $\begin{array}{c}\text { demand-load } \\
\text { shifting } \\
\text { (DLS) }\end{array}$ & $\begin{array}{c}\text { Demand peak } \\
\text { shaving } \\
\text { (DPS) }\end{array}$ & $\begin{array}{l}\text { Flat tariff } \\
\quad(\mathrm{FT})\end{array}$ & $\begin{array}{c}\text { Double } \\
\text { tariff } \\
\text { (DT) }\end{array}$ & $\begin{array}{l}\text { Capacity } \\
\text { tariff }\end{array}$ & $\begin{array}{l}\text { Feed-in } \\
\text { limit }\end{array}$ \\
\hline $\begin{array}{c}\text { Combination } 1 \\
\text { (Baseline scenario) }\end{array}$ & ON & $\mathrm{OFF}$ & $\mathrm{OFF}$ & $\mathrm{OFF}$ & ON & $\mathrm{OFF}$ & $\mathrm{OFF}$ & $\mathrm{OFF}$ \\
\hline Combination 2 & $\mathrm{ON}$ & OFF & OFF & $\mathrm{ON}$ & ON & OFF & ON & OFF \\
\hline Combination 3 & $\mathrm{ON}$ & OFF & ON & OFF & OFF & ON & OFF & OFF \\
\hline Combination 4 & $\mathrm{ON}$ & $\mathrm{ON}$ & $\mathrm{OFF}$ & $\mathrm{OFF}$ & ON & $\mathrm{OFF}$ & $\mathrm{OFF}$ & ON \\
\hline Combination 5 & ON & ON & ON & ON & $\mathrm{OFF}$ & ON & ON & ON \\
\hline
\end{tabular}




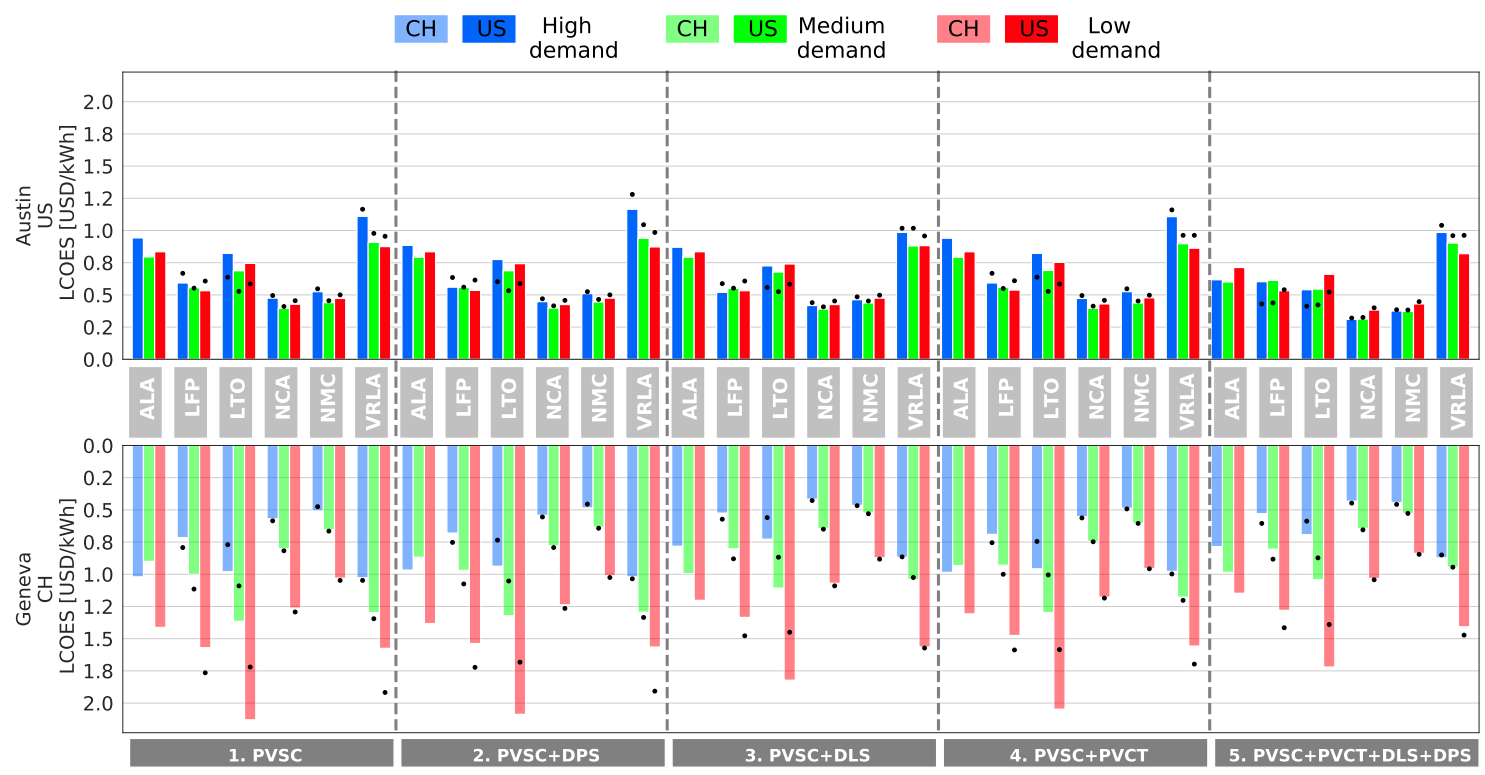

Fig. 3: Levelized cost of energy storage of a $7 \mathrm{kWh}$ battery for all battery technologies depending on the type of combination of applications for Auxtin, U.S. (top) and Geneva, Switzerland (bottom). The size of the PV system correspond to the median installed capacity across both locations (i.e. 4.8 for Geneva and 5 $k W_{p}$ for Austin). The black point in the graph corresponds to the optimization results for the most likely values for every technology in terms of battery pack cost, calendric and cycle lifetime, depth of discharge and round-trip efficiency according to [0] (except for advanced lead-acid, for which there is no public data available beyond the proposed manufacturer). Note that for the LCOES the lower is the bar the better are the results.

\subsection{Levelized cost}

Fig. 3 displays the levelized cost of energy storage for six battery technologies and five combinations of applications in Geneva and Austin. Three major observations can be made. First, NCA and NMC-based batteries offer lower levelised cost for all combinations, the former due to an elevated lifespan and a high number of cycles, while for the latter the reason is a combination of low cost (technology with the lowest cost after VRLA) and a reasonable compromise between number of cycles and lifespan. Secondly, batteries performing in Austin offer lower cost per kWh since they are heavily cycled, (i.e. the average battery in Austin supplies $62 \%$ more electricity throughout its lifetime than in Geneva). As for Geneva, the LCOES also clearly decreases as household electricity consumption increases (demand data for both countries is analyzed in Section 1.1 of Supplementary Information). These results have important implications for the energy transition since residential batteries cycle more for consumers with large electricity consumption and consumers with low consumption could group themselves under communities battery schemes in order to reach lower costs.

Finally, in terms of combination of applications, demand load-shifting increases the use of the battery, reducing the levelized cost, particularly in Geneva where battery use increases on average by $23 \%$ when demand load-shifting is included. This is mainly due to the double 
tariff structure which is applied all year-round and low PV surplus in winter, in contrast to Austin where there is a relatively high PV surplus in winter and the double tariff is applied only during summertime. Accordingly, demand load-shifting reduces the LCOES in average by $14 \%$ in Geneva and by $9 \%$ in Austin.

Additionally, Fig. 3 shows the optimization results for the most likely values for every technology in terms of battery pack cost, calendric and cycle lifetime, depth of discharge and round-trip efficiency according to [40] (except for ALA, for which there is no public data available beyond the proposed manufacturer, for further information see Section 1.5 of the Supplementary Information). These values are very close to the chosen manufacturer. The greater difference corresponds to LTO chemistry, mainly due to the great cost's deviation (i.e. $1650 \mathrm{USD} / \mathrm{kWh}$ in this study vs. $1060 \mathrm{USD} / \mathrm{kWh}$ in [40]).

\subsection{Levelised value}

Fig. 4 displays the levelized value for all battery technologies depending on the combination of applications. The differences among technologies regarding added value per-kWh for combinations that do not include demand peak shaving is relatively small (i.e. less than $9 \%$ for both countries). Conversely, ALA-based and VRLA-based batteries add more and less value per-kWh respectively than other battery chemistries when demand peak shaving is included (on average $25 \%$ and $15 \%$, respectively) because in both cases, less electricity is supplied by the battery due to a shallower depth-of-discharge. However, in the case of ALAbased batteries, the battery is used mostly for demand-peak shaving since it is the application that adds most value and this technology offers significant discharge rating (see Section 3.4). On the other hand, the cash flow is significantly lower for VRLA-based batteries due to low depth-of-discharge (50\%), efficiency (85\%) and crucially the limited power characteristics (i.e. maximum charge and discharge power of $0.1{ }^{*} \mathrm{C}$ ) leading to lower levelized value. In terms of geography, more value per-kWh is added in Geneva (i.e. in average $0.21 \mathrm{USD} / \mathrm{kWh}$ ), compared to Austin. (i.e. in average $0.09 \mathrm{USD} / \mathrm{kWh}$ ), due to higher electricity prices. Furthermore, when excluding demand peak shaving, batteries in households with higher demand create slightly more value per-kWh due to a higher self-consumption. On the other hand, when demand peak shaving is included, batteries in Geneva households with lower demand create more value per-kWh, due to a higher relative influence of the capacity tariff, i.e. the battery is primarily used for demand peak shaving.

The addition of applications such as demand load shifting (combination 3) or avoidance of PV curtailment (combination 4) to the baseline scenario (PV self-consumption referred to as combination 1) adds only marginal value, however, when the four applications are combined, the results are significantly better than the combination of PV self-consumption and demand peak shaving (i.e. value per-kWh is on average $27 \%$ higher). This improvement is due to the synergies between demand load shifting and demand peak shaving (see Section 4 of the Supplementary Information). Demand peak shaving is the application adding most value per-kWh (i.e. 0.11 and $0.15 \mathrm{USD} / \mathrm{kWh}$ in the U.S. and Switzerland, respectively), owing to the importance of the capacity tariff in the final bill even if the bill is revenue neutral when 


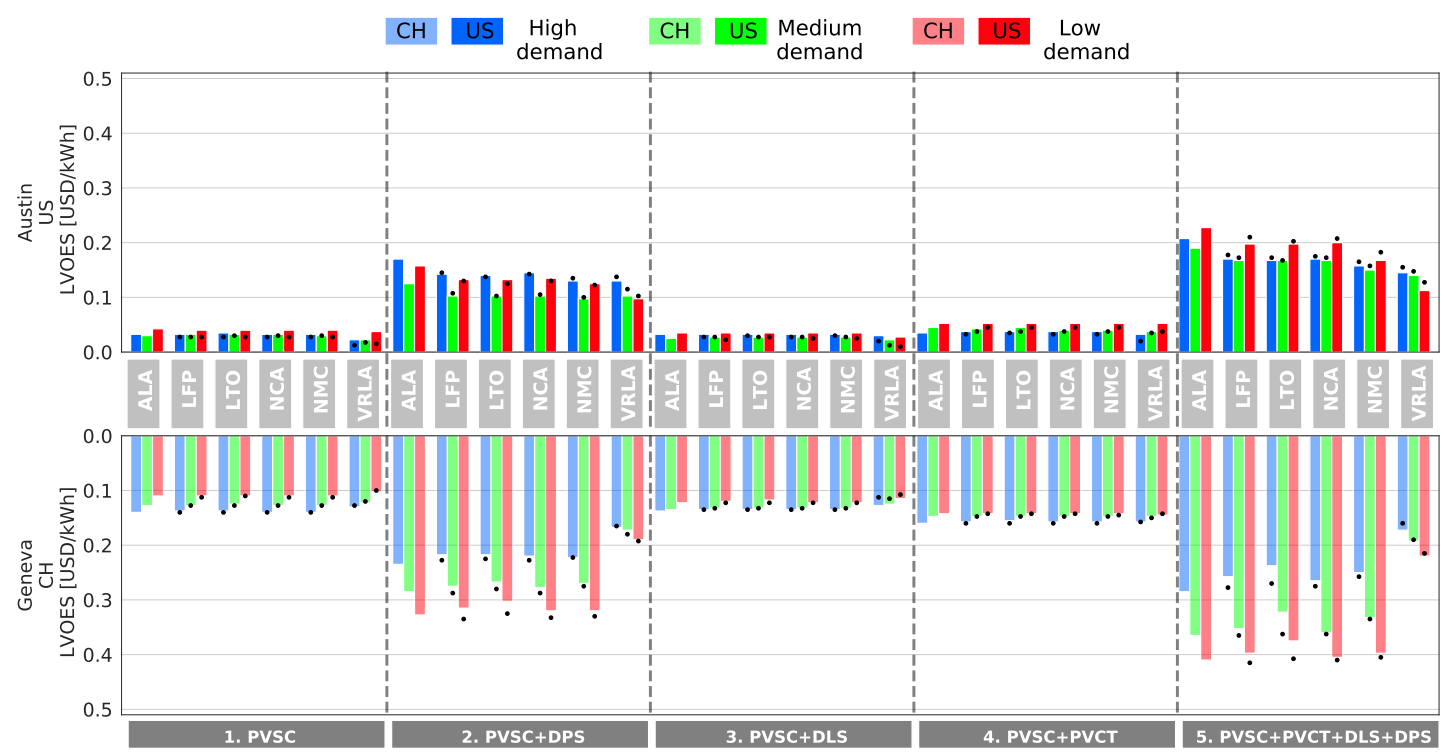

Fig. 4: Levelized value of energy storage of a $7 \mathrm{kWh}$ battery for all battery technologies depending on the type of combination of applications for Austin, U.S. (top) and Geneva, Switzerland (bottom). The size of the PV system correspond to the median installed capacity across both locations (i.e. 4.8 for Geneva and 5 $k W_{p}$ for Austin). The black point in the graph corresponds to the optimization results for the most likely values for every technology in terms of battery pack cost, calendric and cycle lifetime, depth of discharge and round-trip efficiency according to [40] (except for advanced lead-acid, for which there is no public data available beyond the proposed manufacturer). Note that for the LVOES the higher is the bar the better are the results.

it is added. The LVOES obtained When the optimization is run using the most likely values for every technology remains very similar (see the black points in Fig. 4).

\section{3. $N P V$}

Fig. 5 displays the net present value for all battery technologies depending on the type of combination of applications for Geneva and Austin. It can be seen that due to high costs (as well as reduced cycle life, depth-of-discharge and lifespan in the case of VRLA) there is no positive economic case. However, we can see that the profitability is markedly improved for most technologies by combining applications. Since the battery operation adds more value in Geneva than in Austin, the NPV is higher as a result. In the U.S., similar NPV across the consumption brackets is present, with the clear exception of medium demand households using LFP-based batteries. This exception is due to a replacement battery for consumers 3 months before the project lifetime in this consumption bracket, which includes a supplementary investment to replace the battery and therefore further reduces the net present value (the same applies to high demand households for full combination of applications in Austin). In terms of applications, the combination of PV self-consumption with demand peak shaving increases the NPV on average by $15 \%$, which can be improved $6 \%$ more when demand load-shifting is included. The NPV obtained When the optimization is run using 


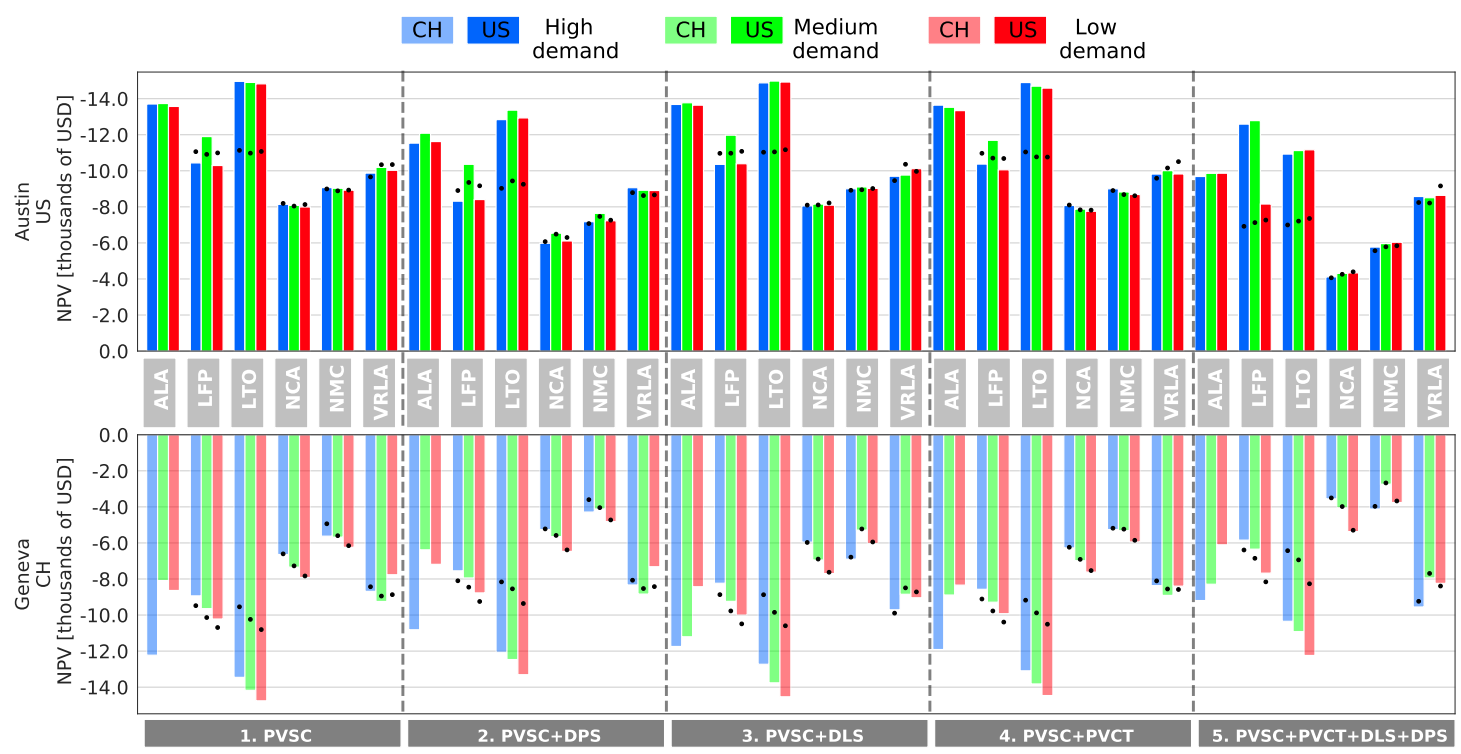

Fig. 5: Net present value of a $7 \mathrm{kWh}$ battery for all battery technologies depending on the type of combination of applications for Austin, U.S. (top) and Geneva, Switzerland (bottom). The size of the PV system correspond to the median installed capacity across both locations (i.e. 4.8 for Geneva and $5 k W_{p}$ for Austin). The black point in the graph corresponds to the optimization results for the most likely values for every technology in terms of battery pack cost, calendric and cycle lifetime, depth of discharge and round-trip efficiency according to [40] (except for advanced lead-acid, for which there is no public data available beyond the proposed manufacturer). Note that the y-axis presents negative NPV for both countries, thus the lower is the bar the better are the results.

the most likely values for every technology remains very similar (see the black points in Fig. 4). The greater difference corresponds to LTO chemistry, mainly due to the great cost's deviation (i.e. $1650 \mathrm{USD} / \mathrm{kWh}$ in this study vs. $1060 \mathrm{USD} / \mathrm{kWh}$ in [40]).

\subsection{Impact of battery size}

Fig. 6 displays the average levelized cost, levelized value and net present value across the three groups of consumers (see Material and methods Section and Section 1.1.1 of Supplementary Information), for small (i.e. $3 \mathrm{kWh}$ ), medium (i.e. $7 \mathrm{kWh}$ ) and large (i.e. $14 \mathrm{kWh}$ ) batteries performing simultaneously all consumer applications depending on the battery technology. Since batteries are heavily cycled in Austin, lower levelized cost is reached. The per-kWh cost difference between the two countries increases when the battery size increases. In Geneva, a large battery incurs higher per-kWh cost due to relatively low number of cycles and higher capital expenditure. In contrast, in Austin, large batteries reduce further the levelized cost.

VRLA and NMC-based batteries increase their added value when the battery size increases. This is due to their lower charge and discharge rates $\left(0.1^{*} \mathrm{C}\right.$ and $0.4^{*} \mathrm{C}$, respectively) which means that they need a large energy capacity to provide significant power, while added value decreases with battery size for other chemistries with larger charge and discharge rates. 

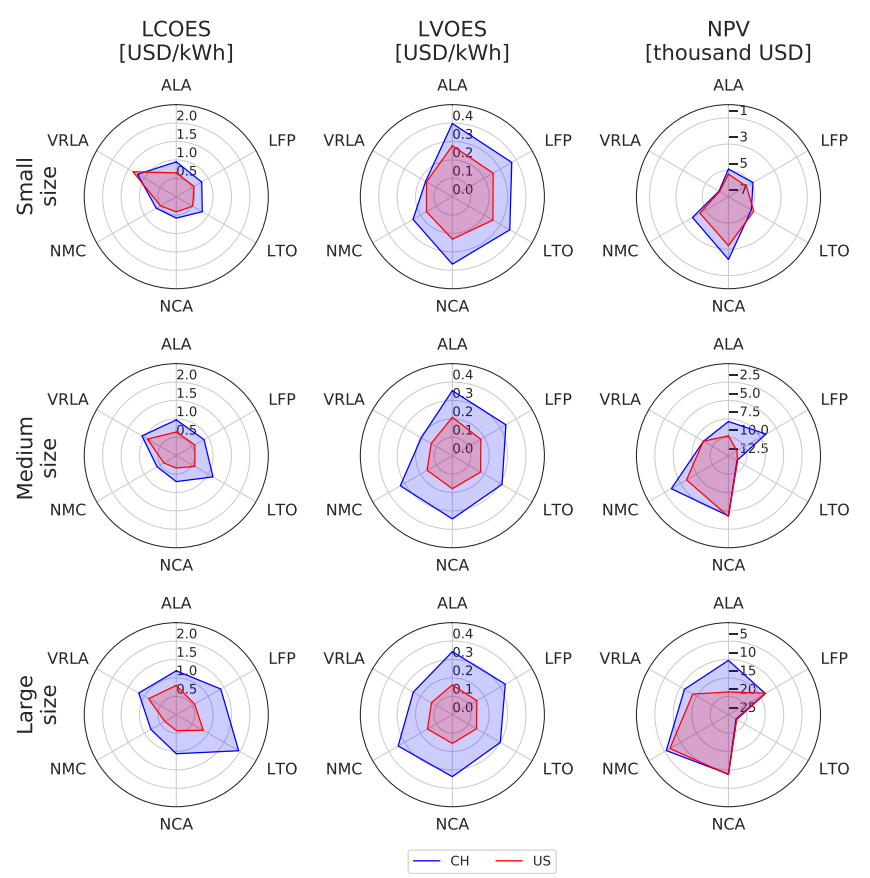

Fig. 6: Comparison of the average LCOES (left), LVOES (middle) and NPV (right) for various battery technologies performing simultaneously all consumer applications in Austin, U.S. (red) and Geneva, Switzerland (blue) depending on the type of annual electricity demand, namely small (top), medium (middle) and large (bottom).

For small size batteries, NCA-based batteries have better results in both countries, whereas VRLA batteries reach worst results for the full combination of applications. NCA-based batteries are preferred in Austin and very competitive with NMC-based batteries in Geneva for medium-sized batteries, while for large-sized batteries NMC chemistry get the better net present value. Overall, the net present value results of Fig. 6indicate that batteries in Geneva are on average $13 \%$ (10\% for small sizes, $16 \%$ for medium sizes and $12 \%$ for large sizes) more attractive than in Austin, due to higher value added as a result of higher electricity electricity prices.

\section{Discussion}

Based on our experiments for Geneva and Austin, we find that NCA and NMC are the best-suited battery technologies for various combinations of applications (i.e. PV selfconsumption, avoidance of PV curtailment, demand load shifting and demand peak shaving). When all the applications are combined NCA is the best-suited battery technology in Austin, which represent a place with high irradiance, in general high electricity consumption, low electricity prices and where the use of air conditioning is extended. On the other hand, NMC-based batteries reach in average a net present value $7 \%$ higher than NCA-based batteries (i.e. NPV is very similar) in Geneva, where electricity consumption and irradiance 
are lower, electricity prices higher and where there is no air conditioning in summer. The household demand marginally affects the profitability of PV-coupled battery systems and we find the NPV difference among the three consumption brackets for all technologies and combinations of applications is less than $10 \%$ (2\% in the U.S. and $8 \%$ in Switzerland, on average). On the other hand, geography impacts the battery's economic viability and the net present value of battery systems in Geneva are on average $16 \%$ more attractive than in Austin, mainly due to higher electricity prices.

Despite significantly increasing the NPV, batteries simultaneously performing several applications are not yet profitable under existing market conditions. However, further (expected) reductions in battery costs, together with combining battery applications may hold the key towards household battery profitability. In particular, adding demand peak shaving to PV selfconsumption brings clear benefits compared to the baseline scenario (PV self-consumption only), especially for NCA and NMC-based batteries (up to $66 \%$ higher NPV). It is expected that demand peak-shaving would also introduce other benefits for the wider energy system, since electricity peaks are typically met by more costly or carbon-intense generators across many countries (this is not however the case of Switzerland where hydropower is used for this purpose). Moreover, distribution system operators could also defer or even save investment in infrastructure. Thus, demand peak shaving is an application which provides synergies for the consumer, utility companies and distribution system operators. Demand load-shifting increases battery use but when demand peak shaving is not included in the combination, it barely increases the net present value, even in Switzerland where double tariff is applied all year-round. Being a regulation-based application, the avoidance of PV curtailment is more interesting from the grid perspective than from the consumer perspective.

In the residential electricity market, small battery sizes offer the best economic case. Despite a higher annual electricity demand in Texas compared to Geneva, larger battery capacities are not economically justified and a small size battery ( $3 \mathrm{kWh}$ in this study) obtains the best results in both locations. However, with (installed) cost reductions of $55 \%$, medium size batteries will get more economically attractive than small size batteries in both countries. From a market perspective, further cost reduction of lithium-ion technologies may result in more market competition for NMC-based batteries which have the strongest position in the market at the moment. For instance, NCA-based batteries are more suitable than NMC-based ones when combining applications mainly due to higher charge and discharge rates, cycles and extended lifespan, even if the price is higher, thus a cost reduction of NCA-based batteries can compromise the leader position of NMC-based batteries in the residential market.

In order to reach economic profitability, battery systems require further cost reductions regardless of battery technology. Installation costs (including permitting, inspection, interconnection, overhead, profit and installation labor) in Geneva and Austin are assumed to be $\$$ 2000 in this study [51, 52] but may reduce with increasing installation experience (learning by doing) and market competition. Fig. 7 displays the break-even point of a $7 \mathrm{kWh}$ battery performing only PV self-consumption as well as all four applications depending on the battery technology and location. The current installation cost per kWh considering battery, inverter and installation are also given for reference purposes. When all applications are 


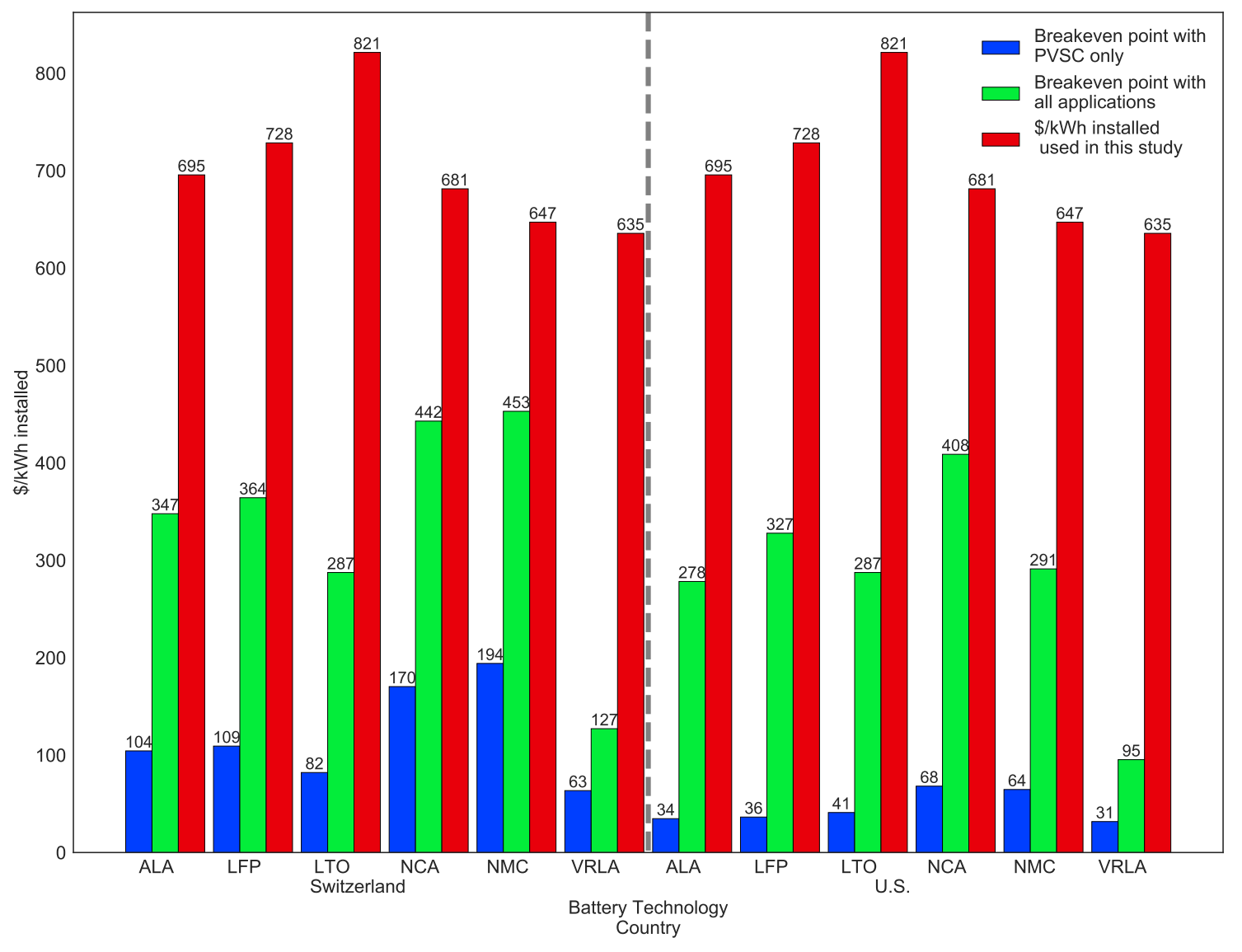

Fig. 7: Break-even point of a $7 \mathrm{kWh}$ battery for all battery technologies depending on the type of combination of applications, PV self-consumption only (blue), the full combination of applications (green) and for comparison, the installed cost per kWh used in this study (red), for the U.S. (right) and Switzerland (left). The size the PV system correspond to the median installed capacity across both locations.

combined, NCA-based batteries are closest to profitability. They require only $35 \%$ reduction in installed costs to be profitable in Switzerland and $40 \%$ in the U.S. NMC-based batteries in Switzerland require a 30\% reduction on installed costs, however, in the U.S. this increases up to $55 \%$. Due to higher electricity prices, profitability may be reached first in Switzerland even if PV self-consumption is the only application, however, on average a reduction of $83 \%$ in the cost per-kWh-installed, compared to today's cost, is required. On the other hand, when all applications are combined, a reduction of $52 \%$ is required. In the case of the U.S., further reductions are needed (93\% if only PV self-consumption is addressed and $60 \%$ if all applications are combined). According to IRENA lithium-ion batteries', installation costs will be reduced by $60 \%$ on current levels by 2030 [38], thus residential batteries may reach profitability (without subsidies) in both countries in the next decade if all applications are combined. This break-even period may be however shorter if electricity prices increase. 
NCA-based batteries already have the appropriate characteristics to combine applications and expand their deployment. LFP-based batteries have suitable technical characteristics but a high number of cycles must be ensured. On the other hand, LTO-based batteries can be considered as over-designed for household needs which leads to higher cost, and if they are over-sized, entail a higher cost than other battery types. NMC-based batteries are expected to lead the cost decline due to their leader position in the market, however, technical specifications, mainly calendar life, will need further development if manufacturers want to keep their dominant position in a near future with residential batteries performing several applications simultaneously. Advanced lead-acid batteries have competitive characteristics and performance, however, shallow depth-of-discharge and high costs, penalize them when compared with lithium-ion technologies. Therefore, only aggressive cost reductions and significant technical improvements could lead to increase their market share. The environmental dimension can be an important asset for this technology since its recycling process has been already established and other criteria such as their material criticality is far lower compared to lithium-ion batteries [58]. Finally, already-mature traditional lead-acid batteries, which have limited margin for improvement, are clearly less attractive for exploiting additional applications which appears to be a strategy that cannot be ignored.

\section{Conclusions}

The aim of this study was to determine the best-suited battery technology for various combination of applications (i.e. PV self-consumption, avoidance of PV curtailment, demand load shifting and demand peak shaving) for two locations with different irradiance profiles, electricity prices and average demand consumption (i.e. Austin, U.S. and Geneva, Switzerland) and taking into account three battery sizes (i.e. 3, 7 and $14 \mathrm{kWh}$ ). We found that NCA and NMC are the best-suited batteries in both locations and for all the combinations of applications, being NCA slightly better in the U.S. example than NMC-based batteries.

Moreover, emerging from the present study, we contribute with four factors that influence the economic profitability of a PV-coupled battery system: (a) The low influence of annual household demand, which in this study varies from $4.9 \%$ in Austin to $2.2 \%$ in Geneva; (b) the rather high impact of location (i.e. 18\% higher NPV in Geneva than in Austin), whose uncertainty is rather low since the electricity bill structure and environmental factors are widely known; (c) the medium impact of battery technology which depends not only on the technical characteristics, which are already good for residential applications, but as well on battery costs which are still high for the same niche and whose uncertainty is rather high; (d) the impact of the combination of applications, which can be marked, especially with demand peak shaving, but there is rather high uncertainty since the number of applications depends on local regulation by utility companies and policy makers.

Although our study proposes a robust framework to quantify the attractiveness of batteries and the proposed models are rich in technology details, it is not without limitations, which in turn call for future research. Other forecast strategies different to perfect forecast could be introduced in the optimization framework, with this reducing the revenue. In addition, 
the design of future electricity tariffs including time-of-use and capacity components is still a topic under investigation. In particular, capacity tariffs are expected to become more widespread since they offer great cost reflectivity as well as revenue variability for network businesses in the face of current and expected disruptions and conduct to flexibility [59]. Additionally, while the scope of the research presented in this paper is limited to electricity demand in dwellings, future research should also incorporate heat and transport demand and the trade-offs of different low carbon technologies such as residential batteries, heat pumps and electric vehicles. Finally, the proposed optimization framework could be extended to more geographies.

The open-source model used in this study is publicly available in https://github.com/ alefunxo/Basopra, and could be used for different PV generation profiles and demand profiles, as well as different tariff structures and batteries with user-defined characteristics.

\section{Acknowledgement}

This research project was financially supported by the Swiss Innovation Agency Innosuisse and is part of the Swiss Competence Center for Heat and Electricity Storage (SCCER$\mathrm{HaE}$ ), while also contributing to the Competence Center for Research in Energy, Society and Transition (CREST). We would like to thank Pecan Street Project for providing the demand data for the U.S.

\section{Author contributions}

A.P.B. formulated and verified the model, performed the research, analyzed the data and wrote the paper; D.P. designed and coordinated the study; D.P. and M.P. supervised the research; E.B. verified the model and designed the demand clustering; M.C.G. provided

guidance on the demand clustering and the manuscript preparation. All authors gave their final approval for publication.

\section{Additional information}

Supplementary Information accompanies this paper at doi XX

Competing interests: The authors declare no competing interests. 


\section{References}

[1] Fu R, Feldman DJ, Margolis RM, Woodhouse MA, Ardani KB. US solar photovoltaic system cost benchmark: Q1 2017. Golden, CO: National Renewable Energy Laboratory (NREL). NREL/TP-6A20-68925; (2017). [Accessed on 27/05/2019] https://www.nrel.gov/docs/fy17osti/68925.pdf.

[2] Bundesnetzagentur. Zahlen, Daten, Informationen zum EEG; $2017 . \quad$ [Accessed on 27/05/2019] https://www.bundesnetzagentur.de/DE/Sachgebiete/ ElektrizitaetundGas/Unternehmen_Institutionen/ErneuerbareEnergien/

ZahlenDatenInformationen/zahlenunddaten-node.html.

[3] Recent facts about photovoltaics in Germany. Fraunhofer ISE; 2018. [Accessed on 27/05/2019] https://www.ise.fraunhofer.de/content/dam/ise/en/documents/ publications/studies/recent-facts-about-photovoltaics-in-germany.pdf.

[4] Eurostat. Electricity prices for household consumers - bi-annual data (from 2007 onwards); 2018. [Accessed on 27/05/2019] http://appsso.eurostat.ec.europa.eu/nui/ show.do?dataset=nrg_pc_204\&lang=en.

[5] Pyrgou A, Kylili A, Fokaides PA. The future of the Feed-in Tariff (FiT) scheme in Europe: The case of photovoltaics. Energy Policy. 2016;95:94-102. https://doi.org/ 10.1016/j.enpol.2016.04.048.

[6] Pius Husser. National Survey Report of PV Power Applications in Switzerland 2016. Nova Energie GmbH / IEA PVPS; 2017. [Accessed on 27/05/2019] http: //iea-pvps.org/index.php?id=93\&eID=dam_frontend_push\&docID=4055.

[7] Luthander R, Widén J, Nilsson D, Palm J. Photovoltaic self-consumption in buildings: A review. Appl Energy. 2015;142:80-94. https://doi.org/10.1016/ j.apenergy.2014.12.028.

[8] IRENA. REthinking Energy 2017: Accelerating the global energy transformation. International Renewable Energy Agency; 2017. Abu Dhabi. [Accessed on 27/05/2019] https://www.irena.org/-/media/Files/IRENA/Agency/ Publication/2017/IRENA_REthinking_Energy_2017.pdf.

[9] CPUC. Self-Generation Incentive Program; 2017. California, U.S. [Accessed on 27/05/2019] https://www.cpuc.ca.gov/sgip/.

[10] Figgener J, Habershusz D, Kairies KP, Wessels O, Tepe B, Sauer DU. Wissenschaftliches Mess-und Evaluierungsprogramm Solarstromspeicher 2.0. ISEA and RWTH Aachen University; 2017. [Accessed on 27/05/2019] http://www.speichermonitoring.de/fileadmin/user_upload/ Speichermonitoring_Jahresbericht_2017_ISEA_RWTH_Aachen.pdf.

[11] Energy FBN. New Energy Outlook 2017. Global overview; 2018. [Accessed on 27/05/2019] https://www.res4med.org/wp-content/uploads/2017/06/ BNEF_NE02017_ExecutiveSummary.pdf. 
[12] Hesse HC, Martins R, Musilek P, Naumann M, Truong CN, Jossen A. Economic Optimization of Component Sizing for Residential Battery Storage Systems. Energies. 2017;10. https://doi.org/10.3390/en10070835.

[13] Pena-Bello A, Burer M, Patel MK, Parra D. Optimizing PV and grid charging in combined applications to improve the profitability of residential batteries. J Energy Storage. 2017;13:58-72. https://doi.org/10.1016/j.est.2017.06.002.

[14] Nyholm E, Goop J, Odenberger M, Johnsson F. Solar photovoltaic-battery systems in Swedish households ? Self-consumption and self-sufficiency. Appl Energy. 2016;183:148159. https://doi.org/10.1016/j.apenergy.2016.08.172.

[15] Magnor D, Sauer DU. Optimization of PV battery systems using genetic algorithms. Energy Procedia. 2016;99:332-340. https://doi.org/10.1016/j.egypro.2016.10.123.

[16] Barbour E, González MC. Projecting battery adoption in the prosumer era. Appl Energy. 2018;215:356-370. https://doi.org/10.1016/j.apenergy.2018.01.056.

[17] Stephan A, Battke B, Beuse MD, Clausdeinken JH, Schmidt TS. Limiting the public cost of stationary battery deployment by combining applications. Nat Energy. 2016;1. https://doi.org/10.1038/nenergy.2016.79.

[18] Parra D, Patel MK. The nature of combining energy storage applications for residential battery technology. Appl Energy. 2019;239:1343-1355. https://doi.org/10.1016/ j.apenergy.2019.01.218.

[19] Muller M, Viernstein L, Truong CN, Eiting A, Hesse HC, Witzmann R, et al. Evaluation of grid-level adaptability for stationary battery energy storage system applications in Europe. J Energy Storage. 2017;9:1-11. https://doi.org/10.1016/j.est.2016.11.005.

[20] Böcker B, Kippelt S, Weber C, Rehtanz C. Storage valuation in congested grids. IEEE Trans Smart Grid. 2017; https://doi.org/10.1109/TSG.2017.2721982.

[21] Battke B, Schmidt TS, Grosspietsch D, Hoffmann VH. A review and probabilistic model of lifecycle costs of stationary batteries in multiple applications. Renew Sust Energ Rev. 2013 Sep;25:240-250. https://doi.org/10.1016/j.rser.2013.04.023.

[22] Kazhamiaka F, Jochem P, Keshav S, Rosenberg C. On the influence of jurisdiction on the profitability of residential photovoltaic-storage systems: A multi-national case study. Energy Policy. 2017;109:428-440. https://doi.org/10.1016/j.enpol.2017.07.019.

[23] von Appen J, Braslavsky JH, Ward JK, Braun M. Sizing and grid impact of PV battery systems-a comparative analysis for Australia and Germany. In: Smart Electric Distribution Systems and Technologies (EDST), 2015 International Symposium on; 2015. p. 612-619. https://doi.org/10.1109/SEDST.2015.7315280.

[24] Parra D, Patel MK. Effect of tariffs on the performance and economic benefits of PVcoupled battery systems. Appl Energy. 2016;164:175-187. https://doi.org/10.1016/ j.apenergy.2015.11.037. 
[25] Sani Hassan A, Cipcigan L, Jenkins N. Optimal battery storage operation for PV systems with tariff incentives. Appl Energy. 2017;203:422-441. https://doi.org/10.1016/ j.apenergy.2017.06.043.

[26] Fares RL, Webber ME. The impacts of storing solar energy in the home to reduce reliance on the utility. Nat Energy. 2017;2. https://doi.org/10.1038/nenergy.2017.1.

[27] Zheng M, Meinrenken CJ, Lackner KS. Agent-based model for electricity consumption and storage to evaluate economic viability of tariff arbitrage for residential sector demand response. Appl Energy. 2014;126:297-306. https://doi.org/10.1016/ j.apenergy.2014.04.022.

[28] Tant J, Geth F, Six D, Tant P, Driesen J. Multiobjective Battery Storage to Improve PV Integration in Residential Distribution Grids. IEEE Trans Sustain Energy. 2013;4(1):182-191. https://doi.org/10.1109/TSTE.2012.2211387.

[29] Santos JM, Moura PS, de Almeida AT. Technical and economic impact of residential electricity storage at local and grid level for Portugal. Appl Energy. 2014;128:254 - 264. https://doi.org/10.1016/j.apenergy.2014.04.054.

[30] Hoppmann J, Volland J, Schmidt TS, Hoffmann VH. The economic viability of battery storage for residential solar photovoltaic systems ? A review and a simulation model. Renew Sust Energ Rev. 2014;39:1101-1118. https://doi.org/10.1016/ j.rser.2014.07.068.

[31] O'Shaughnessy E, Cutler D, Ardani K, Margolisa R. Solar plus: Optimization of distributed solar PV through battery storage and dispatchable load in residential buildings. Appl Energy. 2018;213:11-21. https://doi.org/10.1016/j.apenergy.2017.12.118.

[32] Pfenninger S, DeCarolis J, Hirth L, Quoilin S, Staffell I. The importance of open data and software: Is energy research lagging behind? Energy Policy. 2017;101:211-215. https://doi.org/10.1016/j.enpol.2016.11.046.

[33] Pfenninger S. Energy scientists must show their workings. Nat News. 2017;542(7642):393. https://doi.org/10.1038/542393a.

[34] Pfenninger S, Staffell I. Long-term patterns of European PV output using 30 years of validated hourly reanalysis and satellite data. Energy. 2016;114:1251-1265. https: //doi.org/10.1016/j.energy.2016.08.060.

[35] BFE. Erneuerbare Energien Einspeisevergtung Berichte; 2018. [Accessed on 27/05/2019] https://www.bfe.admin.ch/bfe/de/home/foerderung/erneuerbare-energien/ einspeiseverguetung.html\#kw-82976.

[36] NREL. The Open PV Project;. [Accessed on 27/05/2019] https://openpv.nrel.gov/.

[37] AEMC. 2014 Residential Electricity Price Trends; 2014. [Accessed on 27/05/2019] https://www.aemc.gov.au/markets-reviews-advice/2014-residentialelectricity-price-trends. 
[38] IRENA. Electricity storage and renewables: costs and markets to 2030. International Renewable Energy Agency; 2017. Abu Dhabi.[Accessed on 27/05/2019] https://www.irena.org/-/media/Files/IRENA/Agency/Publication/2017/0ct/ IRENA_Electricity_Storage_Costs_2017.pdf.

[39] Lim CS, Yurukoglu A. Dynamic Natural Monopoly Regulation: Time Inconsistency, Moral Hazard, and Political Environments. J Political Econ. 2018;126(1):263-312. https://doi.org/10.1086/695474.

[40] Schmidt T, Beuse M, Xiaojin Z, Steffen B, Schneider S, Pena-Bello A, et al. Additional emissions and cost from storing electricity in stationary battery systems. Environ Sci Technol. 2019;53(7):3379-3390. https://doi.org/10.1021/acs.est.8b05313.

[41] ITP Renewables. Battery Test Centre - Public Report 1. Lithium Ion Battery Test Centre program; 2016. [Accessed on 27/05/2019] http://batterytestcentre.com.au/ wp-content/uploads/2017/07/Battery-Testing-Report-1_web.pdf.

[42] ITP Renewables. Battery Test Centre - Public Report 2. Lithium Ion Battery Test Centre program; 2017. [Accessed on 27/05/2019] http://batterytestcentre.com.au/ wp-content/uploads/2017/07/Battery-Testing-Report-2_web.pdf.

[43] Tesla. Powerwall 2 DC; 2015. [Accessed on 27/05/2019] https://www.solahart.com.au/ media/2849/powerwall-2-dc_datasheet_english.pdf.

[44] Trina BESS. S Series NCA type battery; 2017. [Accessed on 27/05/2019] http:// www.trinaenergystorage.com/uploads/download/149560986943.pdf.

[45] Sony. Fortelion Energy Storage Module and System; 2017. [Accessed on 27/05/2019] https://zerohomebills.com/wp-content/uploads/SONY-Fortelion.pdf.

[46] Leclanche. TiRack Energy Storage Systems; 2015. [Accessed on 27/05/2019] https://www.leclanche.com/wp-content/uploads/2019/04/LECLANCHE-M2-LTOmoduleWEB.pdf.

[47] Sonnenschein. Handbook for Gel-VRLA-Batteries; 2013. [Accessed on 27/05/2019] http://www.sonnenschein.org/PDF\%20files/GelHandbookPart2.pdf.

[48] Ecoult. Ultraflex product fact sheet; $2017 . \quad$ [Accessed on 27/05/2019] https://ecosmartsolar.com.au/wp-content/uploads/2017/08/ Ecoult_UltraFlex_FS_4pp_1702.pdf.

[49] Sauer DU, Merk P, Ecker M, Gerschler JB, Magnor D. Concept of a Battery Aging Model for Lithium-Ion Batteries Considering the Lifetime Dependency on the Operation Strategy. In: 24th European Photovoltaic Solar Energy Conference, 21-25 September, Hamburg, Germany; 2009. p. 3128-3134. https://doi.org/10.4229/24thEUPVSEC20094B0.11.3.

[50] VictronEnergy. EasySolar 12/1600/70; 2017. [Accessed on 27/05/2019] https:// www.victronenergy.no/upload/documents/Datasheet-EasySolar-1600VA-EN.pdf. 
[51] Ardani K, O’Shaughnessy E, Fu R, McClurg C, Huneycutt J, Margolis R. Installed Cost Benchmarks and Deployment Barriers for Residential Solar Photovoltaics with Energy Storage: Q1 2016. Golden, CO: National Renewable Energy Laboratory (NREL). NREL/TP-7A40-67474; 2017. [Accessed on 27/05/2019] https://www.nrel.gov/docs/ fy17osti/67474.pdf.

[52] Baumann T, Baumgartner F. Home Batteriespeicher, studie für solarspar. ZHAW / IEFE Winterthur; 2017. [Accessed on 27/05/2019] https://www.nrel.gov/docs/ fy17osti/67474.pdf.

[53] Käbitz S, Gerschler JB, Ecker M, Yurdagel Y, Emmermacher B, André D, et al. Cycle and calendar life study of a graphite - LiNi1/3Mn1/3Co1/3O2 Li-ion high energy system. Part A: Full cell characterization. J Power Sources. 2013;239:572-583. https://doi.org/10.1016/j.jpowsour.2013.03.045.

[54] Burger B, Rüther R. Inverter sizing of grid-connected photovoltaic systems in the light of local solar resource distribution characteristics and temperature. Solar Energy. 2006;80(1):32-45. https://doi.org/10.1016/j.solener.2005.08.012.

[55] Hart WE, Laird C, Watson JP, Woodruff DL. Pyomo-optimization modeling in python. vol. 67. Springer; 2012. ISBN: 978-1-4614-3226-5.

[56] Beck T, Kondziella H, Huard G, Bruckner T. Assessing the influence of the temporal resolution of electrical load and PV generation profiles on self-consumption and sizing of PV-battery systems. Appl Energy. 2016;173:331 - 342. https://doi.org/10.1016/ j.apenergy.2016.04.050.

[57] Moore M, Counce R, Watson J, Zawodzinski T. A Comparison of the Capital Costs of a Vanadium Redox-Flow Battery and a Regenerative Hydrogen- Vanadium Fuel Cell. J Adv Chem Eng. (2015);5. https://doi.org/10.4172/2090-4568.1000140.

[58] Moss R, Tzimas E, Willis P, Arendorf J, Thompson P, Chapman A, et al.. JRC report on Critical Metals in the Energy Sector; 2013. European Commission Joint Research Centre Institute for Energy and Transport. https://doi.org/doi:10.2790/46338r.

[59] ACCC. Restoring electricity affordability and Australias competitive advantage Retail Electricity Pricing Inquiry Final Report; 2018. [Accessed on 27/05/2019] https://www.accc.gov.au/system/files/Retail\%20Electricity\% 20Pricing $\% 20$ Inquiry $\%$ E $\% 80 \% 94$ Final $\% 20$ Report $\% 20 J u n e \% 202018$.p.pdf. 


\title{
Optimized PV-coupled battery systems for combining applications: impact of battery technology and location
}

\author{
Alejandro Pena-Bello ${ }^{\mathrm{a}, *}$, Edward Barbour ${ }^{\mathrm{b}, \mathrm{c}}$, Marta C. Gonzalez ${ }^{\mathrm{b}, \mathrm{d}, \mathrm{e}}$, Martin K. Patel ${ }^{\mathrm{a}}$, \\ David Parra ${ }^{a}$ \\ ${ }^{a}$ Energy Efficiency Group, Institute for Environmental Sciences and Forel Institute, University of Geneva, \\ Boulevard Carl-Vogt 66, 1205 Genève, Switzerland. \\ ${ }^{b}$ Department of Civil and Environmental Engineering and Engineering Systems, Massachusetts Institute of \\ Technology, 77 Massachusetts Avenue, 1-290, Cambridge, 02139, United States. \\ ${ }^{c}$ Centre for Renewable Energy Systems Technology, Loughborough University, United Kingdom. \\ ${ }^{d}$ Department of City and Regional Planning, UC Berkeley, 406 Wurster Hall, Berkeley, 94720, United \\ States. \\ ${ }^{e}$ Lawrence Berkeley National Laboratory, Cyclotron Road, Berkeley, 94720, United States.
}

\section{Supplementary material and methods}

\subsection{Demand datasets}

Two demand datasets covering Austin, Texas in the U.S. and a western Swiss city with 15minute smart meter data covering the whole year 2015 were used in this study. For Austin the data were obtained from the Pecan Street project, for 308 households, as for the 636 Swiss dwellings data confidentiality agreements apply, however we treated the data as if it was from Geneva. In terms of average yearly electricity consumption the American households use 3.7 times more electricity than Swiss households from the datasets. The two cities present a completely different consumption behavior, while in Austin there is a clear seasonality with a summer peak that is the double of winter or fall consumption, in Geneva summer is the less electricity-demanding season and winter and fall present comparatively only $16 \%$ more electricity demand. In terms of monthly average consumption, in Austin, excluding summer months, the average consumption is $837 \mathrm{kWh} /$ month and almost two times greater during summer months. On the other hand, in Geneva a clear mean of $274 \mathrm{kWh} /$ month is maintained all year-round with a slightly lower consumption in spring and fall (see Fig. 1).

\footnotetext{
*Corresponding author.

Email address: Alejandro.penabello@unige.ch (Alejandro Pena-Bello)
} 

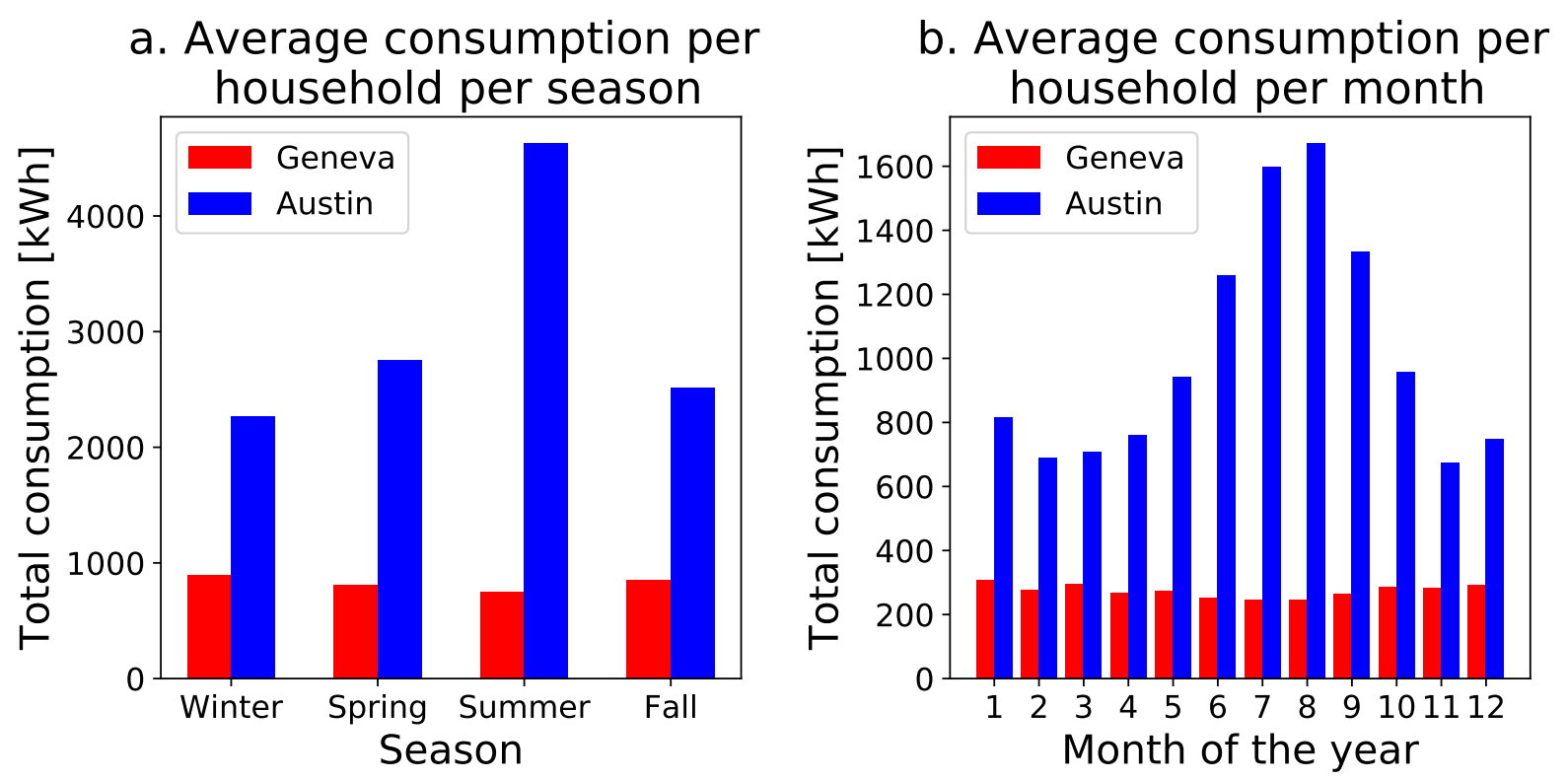

Fig. 1: Average consumption per household in both locations, Geneva, Switzerland is shown in red while Austin, Texas is presented in blue. a. Per season and b. Per month.

\subsubsection{Demand clustering}

Rather than run individual simulations for all the household consumers, which would lead to very long simulation times, we instead aim to find representative consumers which exemplify typical consumption patterns within the data in both countries. Therefore, for both the U.S. and Switzerland we create groups of consumers with similar behavior in terms of the shape and overall magnitude of their average daily load profiles. From each group, we then select the consumer whose load is closest to the centroid of the group, designating that consumer as the representative from that group. Simulations are run for each representative consumer.

To generate the representative consumer groups, we employ a clustering method. In the literature, a range of clustering methods have been employed to form consumer segments (for a review of the clustering techniques applied to electricity load data see [1]), however $\mathrm{k}$-means is the most commonly used clustering framework and has been used in a range of studies regarding household load profiles [2 5]. Therefore, we form our consumer groups using k-means clustering.

When clustering daily load profiles, previous work typically normalizes the load profiles, bringing the daily shapes to a similar scale for pattern recognition [2, 3], as described by Eq. 1 .

$$
e_{c}(t)=\frac{l_{c}(t)}{\sum_{t=1}^{t=24} l_{c}(t)}
$$



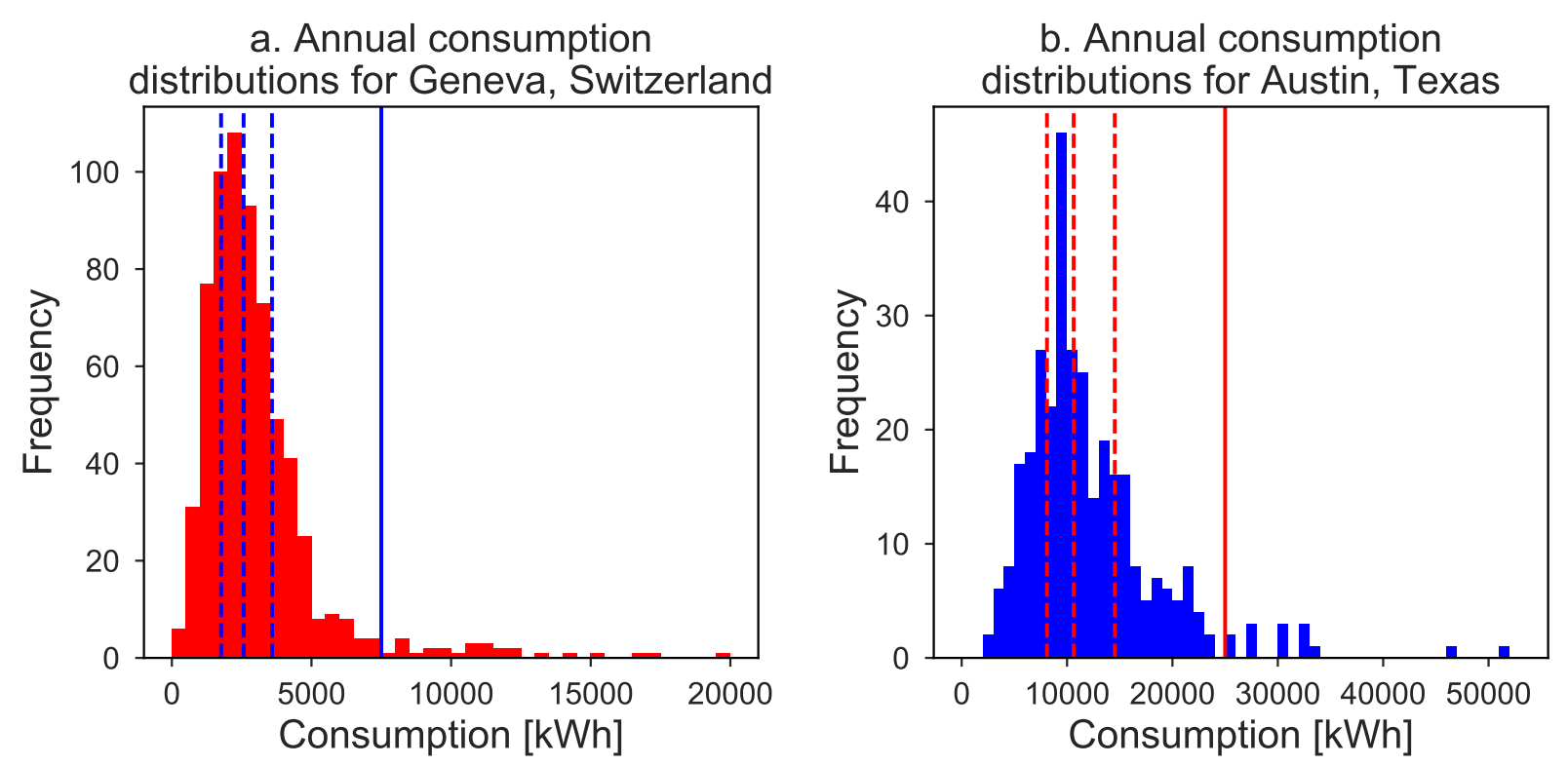

Fig. 2: Electricity consumption in a. Geneva, Switzerland and b. Austin, Texas. The dashed lines represent the dataset first, second (median) and third quartiles and the continuous line marks the limit to outliers.

Where $e_{c}(t)$ is the normalized load at time $t$ and $l_{c}(t)$ is consumer $c$ s load at time $t$ before normalization.

While this approach is successful for forming groups of load profiles with similar shapes independent of consumption magnitudes, in this work we also want to study the effect of differing levels of overall consumption. Therefore, first we look at the distributions of total yearly consumption in both locations and form groups with similar consumption levels. As shown in Fig. 2, we see that there are several consumers with abnormally high consumption in both locations (above $7500 \mathrm{kWh}$ in Switzerland is considered an outlier and above 25000 $\mathrm{kWh}$ in the U.S. is considered an outlier) and we do not consider these consumers, since our ultimate aim is to find representative consumers. We then split the remaining consumers whose consumption is within our defined normal range into 3 separate groups, i.e., a low consumption group, a medium consumption group and a high consumption group in both locations. The low consumption group is defined by consumers in the 0th to 33rd percentiles, the medium consumption group is defined by consumers in the 34th to 66th percentiles, and the high consumption group contains consumers with yearly consumption greater than the 67 th percentile.

After forming the consumption brackets based on overall consumption, we further subdivide these by clustering according to the load shape. Within the 3 consumption brackets the normalized consumer average daily load profiles are clustered to form 4 subgroups in each bracket. We use the k-means clustering method, which randomly assigns an initial set of centroids, and then iteratively moves these to minimize the objective function shown in Eq. 2 . 

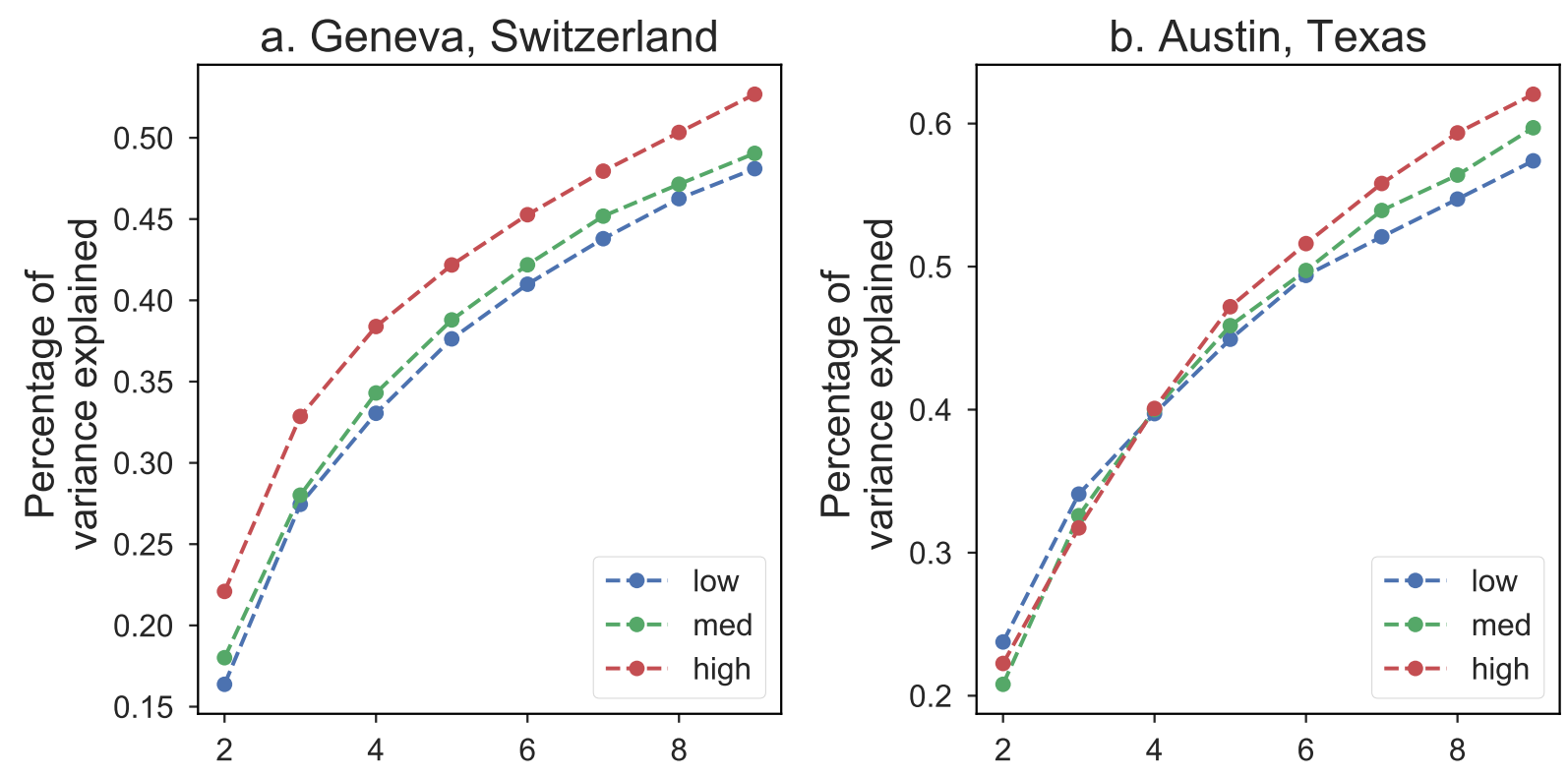

Fig. 3: Percentage of the variance explained in function of the number of clusters used for a. Geneva, Switzerland and b. Austin, Texas for the three electricity consumption brackets (high, medium and low).

$$
J=\sum_{j=1}^{K} \sum_{i=1}^{n_{j}} \sqrt{\sum_{t=1}^{t=24}\left(e_{i, j}(t)-\zeta_{j}(t)\right)^{2}}
$$

Here, $j$ indexes the clusters from 1 to $K$ and $i$ indexes the load shapes assigned to cluster $j$, where $n_{j}$ is the total number of shapes in cluster $j . e_{i, j}$ is the $i$-th load shape assigned to cluster $j$ and $\zeta_{j}$ is the centroid of cluster $j$. As can be seen we minimize the Euclidean distance metric between centroids and the normalized load profiles.

Since we cluster average daily load profiles, we ultimately produce groups with similar average behaviors, recognizing that there may be significant deviation away from the average daily load shape for an individual on any given days [2, 3. We opt to produce 4 clusters in each consumption bracket, noting that the selecting the number of clusters in highly dimensional data where it is not known is a difficult task. However, to provide some justification we look at the variance explained by the cluster centroids compared to the total variance in the data. Fig. 3 shows the elbow plots for both locations, and illustrates that in general the additional variance accounted for through by an extra cluster diminishes below 5-7\% after adding more than four clusters.

\subsection{PV generation}

Environmental variables including outdoor temperature and horizontal solar irradiance monitored across both locations are used to model PV generation. We simulate PV generation 
using a standard one-diode model and PV panel input data with a nominal efficiency of $18.6 \%$, representative of the current state of the art [6]. The model also includes a maximum power point tracker system, as is the case of most PV systems, to maximize the output regardless of the environmental conditions. The PV system's installed capacity is modeled based on the empirical distribution across Switzerland and Texas (see Section 1.3 of the supplementary information). We finally focus on the median PV size of the distributions for our baseline results (i.e. unchanged PV size), while alternative scenarios including the 25th and 75th percentile are shown in Section 5 of the supplementary information.

In order to do a comprehensive comparison, hereon in this section we refer to a generation profile generated for each location using a PV installation of $1 k W_{p}$ of nominal power. In terms of yearly generation, a PV system in Austin generates $15 \%$ more electricity than the same PV system in Geneva. The capacity factor in Austin is 18.8\% while in Geneva is 16.3\%, being these values congruent with related literature [7]. We assume the same generation for every PV system for every household in this study being then adjusted according to the PV size distribution in each location. Fig. 4 presents the differences per season and per month between the two locations, as can be observed throughout the year Austin have more generation than Geneva, except during spring when the PV system in Geneva produces 11\% more electricity than in Austin. As for fall and winter, a PV system in Austin produces $75 \%$ and 34\% more electricity than the same PV system in Geneva, respectively. In summer the difference is less than $6 \%$.

The distribution of PV sizes for both locations and the first, second and third quartiles are presented in Fig. 5. Since A limit of $10 k W_{p}$ of nominal power for residential systems is usually used by national reports [8, 9], we selected the same limit for this study. We take into account all the country installations under the mentioned threshold, as for USA we take only Austin installations under the same threshold. For both datasets the three quartiles are very close, the first quartile is $3.15 \mathrm{~kW}_{p}$ and $3.2 \mathrm{~kW}$ for Austin and Geneva, respectively, as for the third quartile Austin presents a smaller system size $\left(6.4 k W_{p}\right)$ than Geneva (6.9 $\left.k W_{p}\right)$. The medians are again very close, being only $0.2 \mathrm{~kW}$ greater in Austin $\left(5 k W_{p}\right)$ than in Geneva.

\subsection{Electricity tariff and battery applications}

The operation of a residential battery as well as the number of applications it can deliver depends on the tariff structure. In this study we include all existing consumer applications, excluding back-up power since we focus on distribution areas with a high level of grid stability (for both utilities referred in this study, the number of minutes of power failure experienced by a typical customer in a year was below 100 minutes in 2016 . Since there is not a market

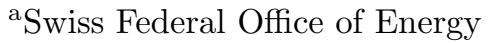

bhttps://openpv.nrel.gov

${ }^{\mathrm{c}}$ For the utility in Texas, the number of minutes of power failure amounted to 95.6 minutes (which is $30 \%$ lower than the average in the U.S. [10] ) while it was only 7.8 minutes in the canton of Geneva.
} 

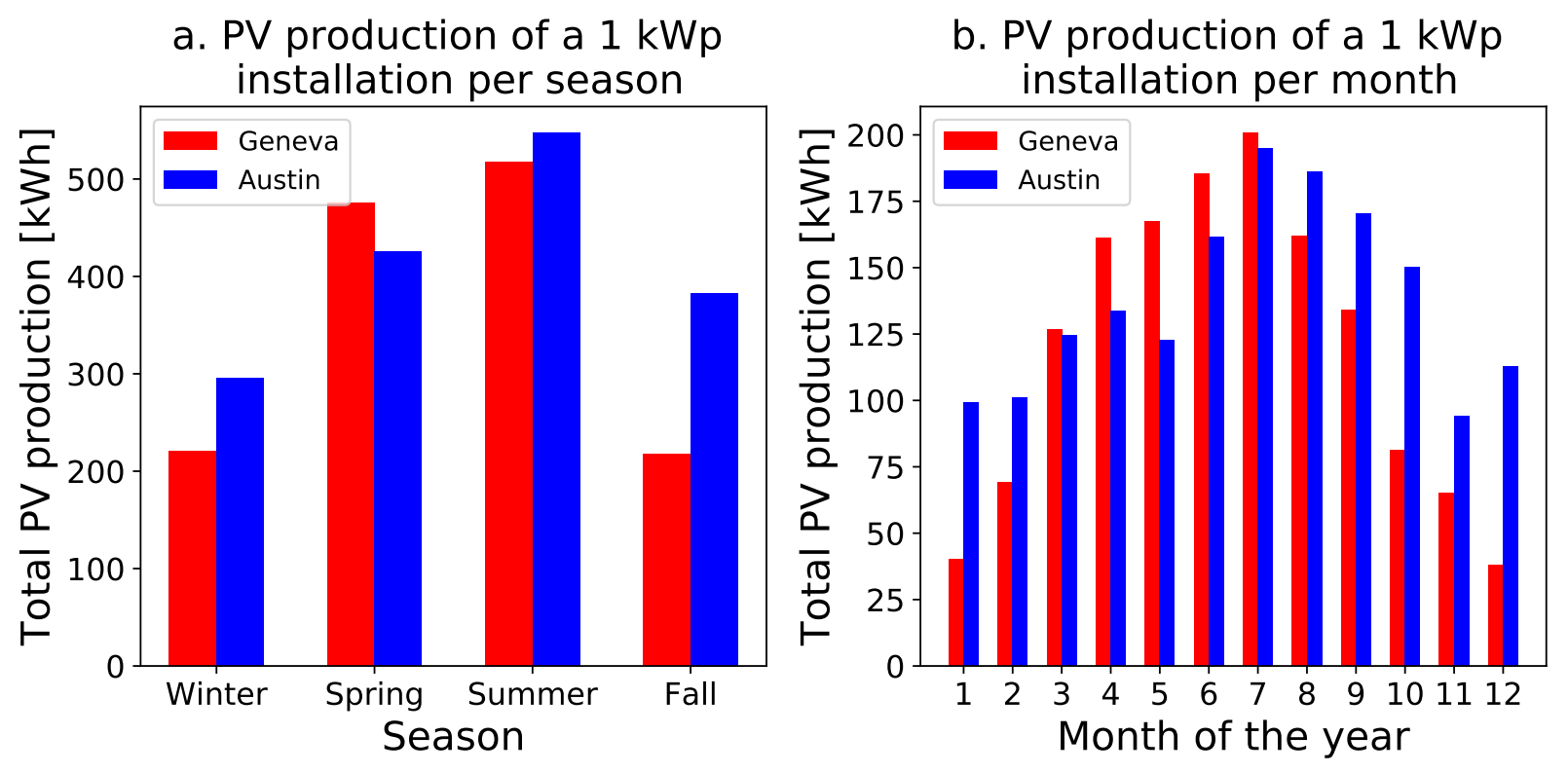

Fig. 4: Electricity generation of a $1 k W_{p}$ PV installation in both locations, Geneva, Switzerland is shown in red while Austin, Texas is presented in blue. a. Per season and b. Per month.
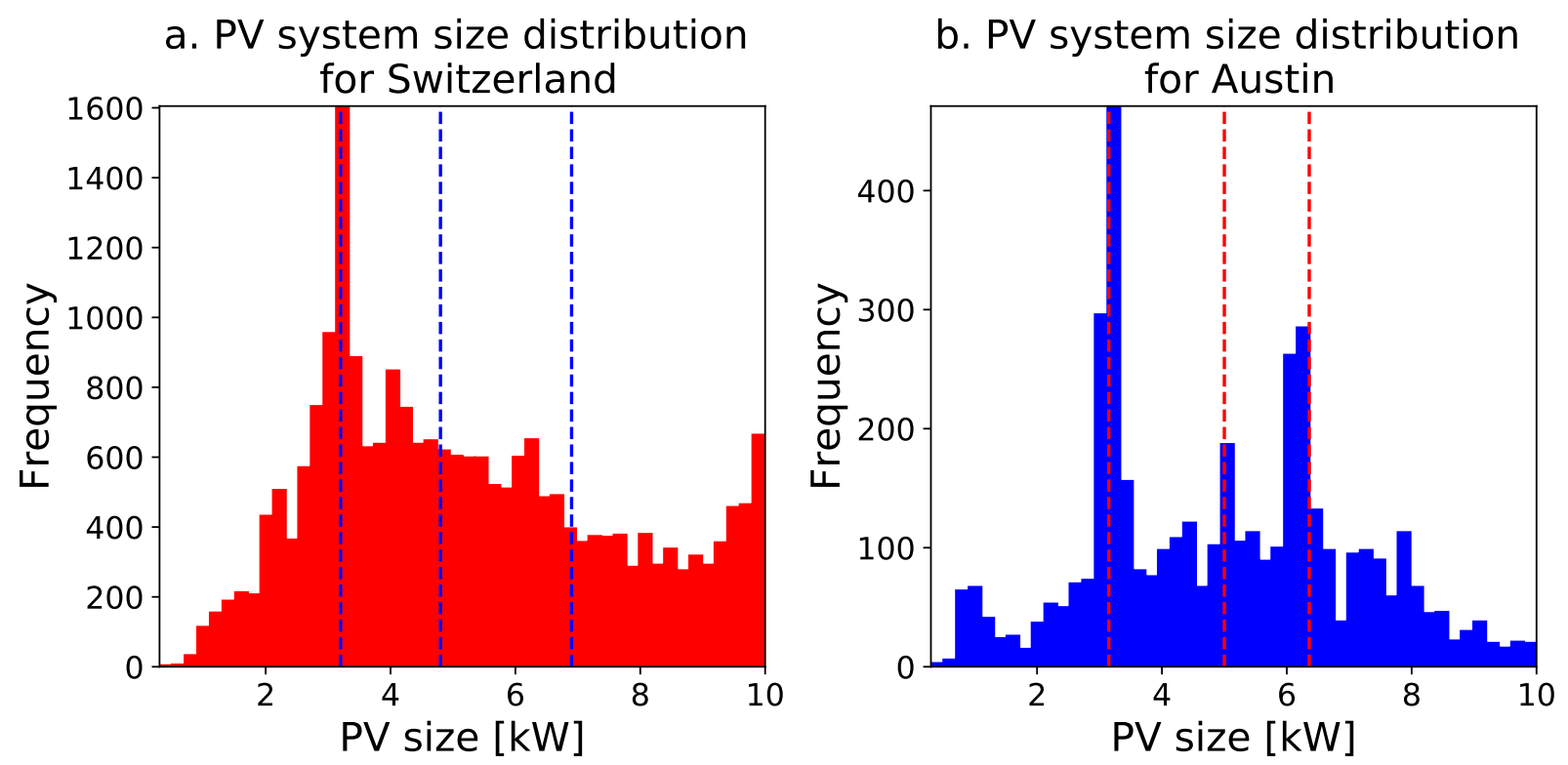

Fig. 5: PV system size distribution smaller than $10 k W_{p}$ for a. Switzerland (22807 data points) and b. Texas (4295 data points). The dashed lines represent the dataset first, second (median) and third quartiles. 
a. Average electricity prices

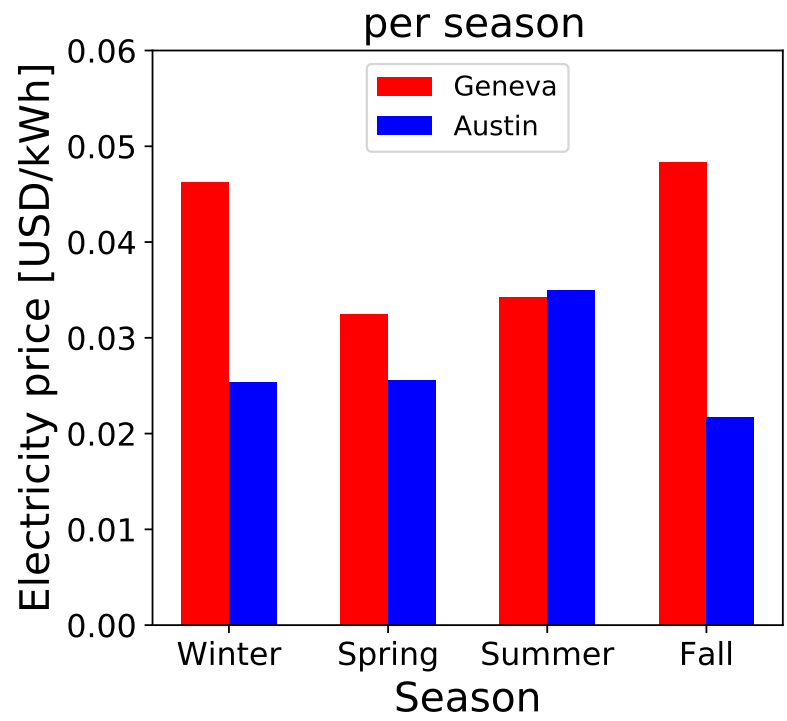

b. Average electricity prices

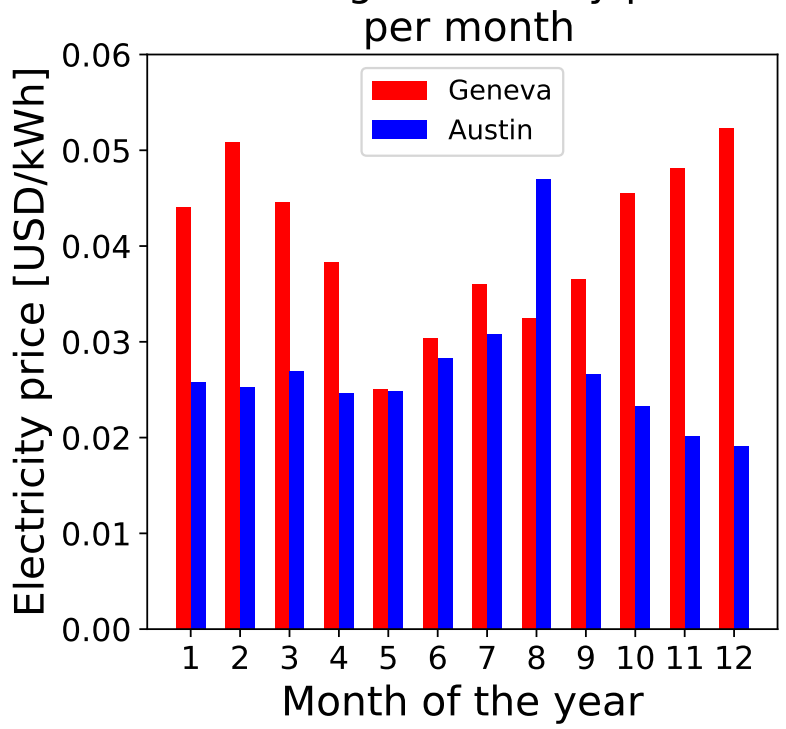

Fig. 6: Electricity prices in both locations, Geneva, Switzerland is shown in red while Austin, Texas is presented in blue. a. Per season and b. Per month.

mechanism incentivizing the export of electricity from residential batteries to the main grid, this case is not considered either.

Energy tariffs are based on Electricit vitale Bleu for households in Geneva and on TOU for residential customers in Austin. Both, single tariffs and double tariffs (with a peak and off-peak periods) are considered in the analysis. In Switzerland, double tariffs are applied all-year-round, while in the U.S. they are applied only in summertime. The export price is assumed to be the wholesale electricity price as is the case for traditional electricity generators. This is already the case in Switzerland for installations which are on the waiting list to be granted a one-off subsidy for the capital investment in PV [9] and this is expected to become a widespread policy as a consequence of falling cost of PV technology.

We use 2015 wholesale electricity prices from the day-ahead market for Texas (ERCOT southern load zone) and Switzerland (EPEXSPOT). In general, Swiss export prices are larger than prices in Texas with average daily prices of $0.04 \mathrm{USD} / \mathrm{kWh}$ and $0.027 \mathrm{USD} / \mathrm{kWh}$ respectively. However, the differences among average electricity prices per season indicate a general trend in Geneva where spring and summer months are usually low (around 0.033 USD/kWh) while fall and winter prices are around 0.047 USD/kWh (see figure 6). As for Austin, prices are similar among winter, spring and fall (around $0.024 \mathrm{USD} / \mathrm{kWh}$ ), however in summer prices are larger (0.035 USD/kWh in average) but can be as high as $2.25 \mathrm{USD} / \mathrm{kWh}$. It is important to note that, apart from the electricity price, electricity bills include other fixed costs as well, such as taxes and grid usage. 


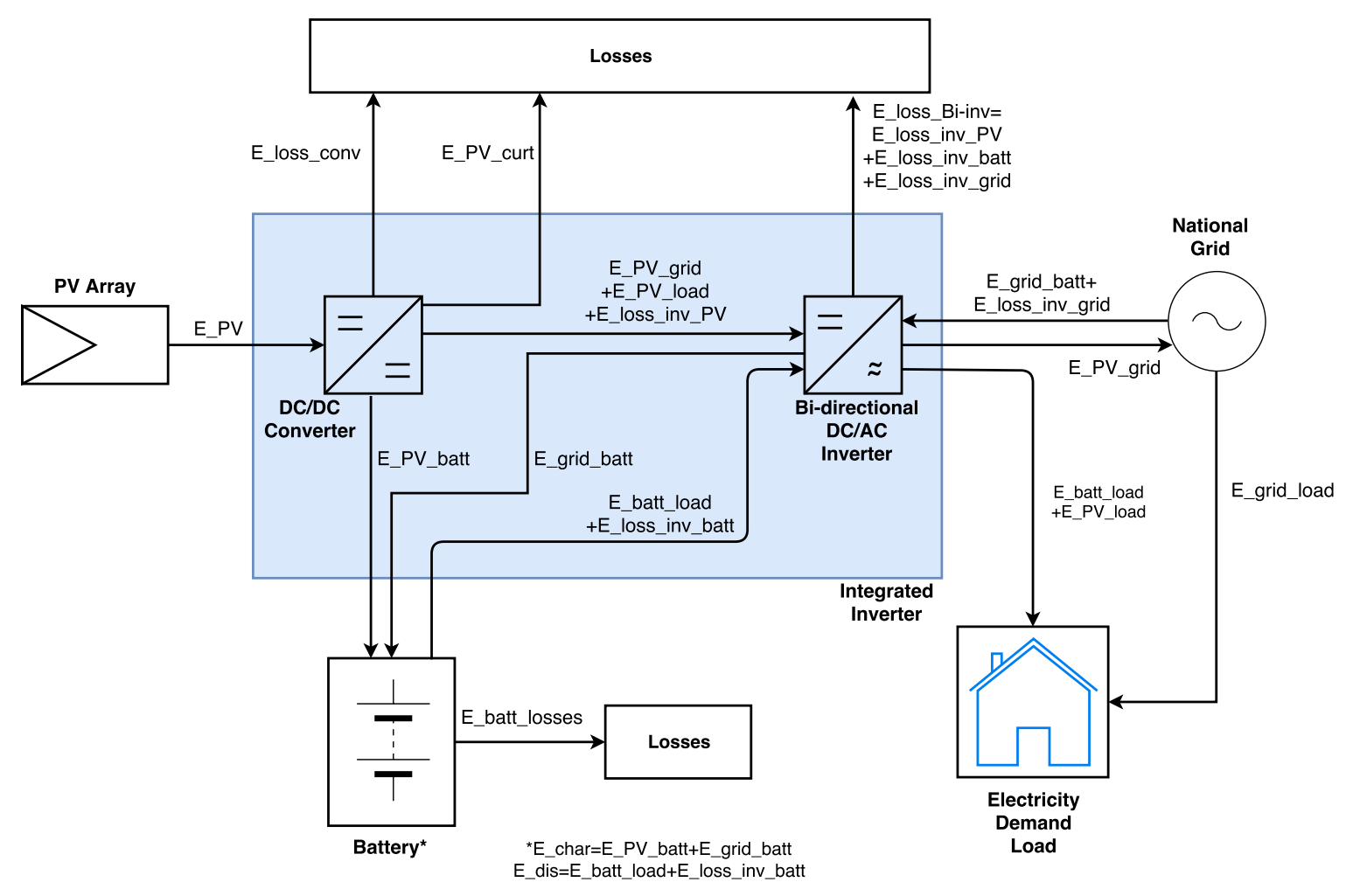

Fig. 7: DC-coupled PV-battery system with integrated inverter used in this study. Arrows indicate the direction of possible energy flows between the individual components.

\subsection{PV-coupled battery system}

The DC-coupled system used in this study is illustrated in Fig. 7 and it includes an integrated inverter with a buck-boost charge controller with a maximum power point tracking system and a bi-directional inverter (required to charge from the grid). An inverter loading ratio (i.e. the ratio between the inverter rating and the PV rating, referred to as ILR) of 1.2 is considered for this study [11].

DC-coupled topology allows to select a smaller inverter (i.e. increase the ratio between the inverter rating and the PV rating beyond 1) and store otherwise clipped energy [? ]. Likewise, this topology prevents from curtailing PV export exceeding a regulatory threshold as in Germany where PV generators with a installed capacity of maximum $30 \mathrm{~kW}$ must be able to reduce the feed-in power in case of network overload or limit the power supply of the PV-system to the grid to $70 \%$ of installed capacity which can be enforced to $50 \%$ if a storage installation is funded by the government subsidy program [12, 13] 呢

DC -coupled systems require a single power conversion to store energy (through the charge

\footnotetext{
${ }^{\mathrm{d}} 9$ subsection 2

${ }^{\mathrm{e}}$ In the literature curtailed and clipped energy are often interchangeable, however in this work we use the term clipped energy to refer to wasted energy due to technical restrictions (e.g. inverter rating) while curtailed energy is used when we refer to wasted energy due to legal restrictions.
} 
controller), whereas AC-coupled systems require two power conversions (from the PV array through the PV inverter and then through a bi-directional inverter to the battery). Therefore, in applications where PV output storage is frequent, DC-coupled systems are generally more efficient than AC-coupled systems. In the DC-coupled system, the efficiency of the charge controller is set at $98 \%$ while that from the bi-directional DC/AC inverter is set at 95\% [14]. Thus, the DC/AC efficiency from the PV system to the grid or to the demand load is $93 \%$. On the other hand, when PV electricity is stored, one must consider battery roundtrip efficiency, therefore lowering efficiency depending on battery technology, for instance, it goes down to $79 \%$ for the VRLA. As for grid charging, the AC-AC efficiency (i.e. grid-to-battery-to-load efficiency) is within a range of $76 \%$ (for VRLA) to $87 \%$ (for LTO). 


\subsection{Most likely cost of stationary batteries}

\begin{tabular}{|c|c|c|c|c|}
\hline Technology & Siting & Parameter & Unit & m. likely \\
\hline NMC & customer & $\begin{array}{l}\text { Battery } \\
\text { Pack Cost }\end{array}$ & $\mathrm{EUR} / \mathrm{kWh}$ & 335 \\
\hline NMC & customer & $\begin{array}{l}\text { O\&M } \\
\text { Cost (fixed) }\end{array}$ & $\begin{array}{l}\text { EUR/kW } \\
\text { p.a. }\end{array}$ & 0 \\
\hline NMC & independent & $\begin{array}{l}\text { Calendric } \\
\text { lifetime }\end{array}$ & $\begin{array}{l}\# \\
\text { years }\end{array}$ & 12 \\
\hline NMC & independent & $\begin{array}{l}\text { Cycle } \\
\text { lifetime }\end{array}$ & $\begin{array}{l}\# \\
\text { cycles }\end{array}$ & 4’996 \\
\hline NMC & independent & DOD & $\%$ & $93 \%$ \\
\hline NMC & independent & $\begin{array}{l}\text { Roundtrip } \\
\text { Efficiency }\end{array}$ & $\%$ & $89 \%$ \\
\hline LFP & customer & $\begin{array}{l}\text { Battery } \\
\text { Pack Cost }\end{array}$ & EUR/kWh & 461 \\
\hline LFP & customer & $\begin{array}{l}\text { O\&M } \\
\text { Cost (fixed) }\end{array}$ & $\begin{array}{l}\text { EUR/kW } \\
\text { p.a. }\end{array}$ & 0 \\
\hline LFP & independent & $\begin{array}{l}\text { Calendric } \\
\text { lifetime }\end{array}$ & $\begin{array}{l}\# \\
\text { years }\end{array}$ & 12 \\
\hline LFP & independent & $\begin{array}{l}\text { Cycle } \\
\text { lifetime }\end{array}$ & $\begin{array}{l}\# \\
\text { cycles }\end{array}$ & 6,529 \\
\hline LFP & independent & DOD & $\%$ & $93 \%$ \\
\hline LFP & independent & $\begin{array}{l}\text { Roundtrip } \\
\text { Efficiency }\end{array}$ & $\%$ & $87 \%$ \\
\hline $\mathrm{NCA}$ & customer & $\begin{array}{l}\text { Battery } \\
\text { Pack Cost }\end{array}$ & EUR/kWh & 281 \\
\hline $\mathrm{NCA}$ & customer & $\begin{array}{l}\text { O\&M } \\
\text { Cost (fixed) }\end{array}$ & $\begin{array}{l}\text { EUR/kW } \\
\text { p.a. }\end{array}$ & 0 \\
\hline $\mathrm{NCA}$ & independent & $\begin{array}{l}\text { Calendric } \\
\text { lifetime }\end{array}$ & $\begin{array}{l}\# \\
\text { years }\end{array}$ & 12 \\
\hline $\mathrm{NCA}$ & independent & $\begin{array}{l}\text { Cycle } \\
\text { lifetime }\end{array}$ & $\begin{array}{l}\# \\
\text { cycles }\end{array}$ & 2'498 \\
\hline $\mathrm{NCA}$ & independent & DOD & $\%$ & $93 \%$ \\
\hline $\mathrm{NCA}$ & independent & $\begin{array}{l}\text { Roundtrip } \\
\text { Efficiency }\end{array}$ & $\%$ & $89 \%$ \\
\hline LTO & customer & $\begin{array}{l}\text { Battery } \\
\text { Pack Cost }\end{array}$ & $\mathrm{EUR} / \mathrm{kWh}$ & 900 \\
\hline LTO & customer & $\begin{array}{l}\text { O\&M } \\
\text { Cost (fixed) }\end{array}$ & $\begin{array}{l}\text { EUR/kW } \\
\text { p.a. }\end{array}$ & 0 \\
\hline LTO & independent & $\begin{array}{l}\text { Calendric } \\
\text { lifetime }\end{array}$ & $\begin{array}{l}\# \\
\text { years }\end{array}$ & 23 \\
\hline LTO & independent & $\begin{array}{l}\text { Cycle } \\
\text { lifetime }\end{array}$ & $\begin{array}{l}\# \\
\text { cycles }\end{array}$ & $15^{\prime} 000$ \\
\hline LTO & independent & DOD & $\%$ & $100 \%$ \\
\hline LTO & independent & $\begin{array}{l}\text { Roundtrip } \\
\text { Efficiency }\end{array}$ & $\%$ & $91 \%$ \\
\hline VLA & customer & $\begin{array}{l}\text { Battery } \\
\text { Pack Cost }\end{array}$ & EUR/kWh & 263 \\
\hline VRLA & customer & $\begin{array}{l}\text { O\&M } \\
\text { Cost (fixed) }\end{array}$ & $\begin{array}{l}\text { EUR/kW } \\
\text { p.a. }\end{array}$ & 0 \\
\hline VRLA & independent & $\begin{array}{l}\text { Calendric } \\
\text { lifetime }\end{array}$ & $\begin{array}{l}\# \\
\text { years }\end{array}$ & 9 \\
\hline VRLA & independent & $\begin{array}{l}\text { Cycle } \\
\text { lifetime }\end{array}$ & $\begin{array}{l}\# \\
\text { cycles }\end{array}$ & 1'500 \\
\hline VRLA & independent & DOD & $\%$ & $55 \%$ \\
\hline VRLA & independent & $\begin{array}{l}\text { Roundtrip } \\
\text { Efficiency }\end{array}$ & $\%$ & $75 \%$ \\
\hline
\end{tabular}

Table 1: Distribution parameters for technology characteristics and cost parameters in 15 


\section{Aging}

Battery aging and durability are parameters with a great uncertainty for battery energy storage technologies [16]. In this paper, we model battery aging process through the battery capacity depletion since it limits the battery lifetime. The aging behavior is typically divided in two, calendar aging (when the battery is standby) and cycle aging (when the battery is used) [17]. We acknowledge the battery aging process is non-linear, particularly in the first hundreds of cycles, but as pointed out in earlier papers, capacity losses can be assumed to be linear without compromising lifetime predictions markedly [17, 18] and this approach is followed in this study. Furthermore, previous studies have reported that one of the two aging factors dominates (typically cycle aging for small batteries) in typical operation conditions [17, thus the model can be simplified across the different technologies through the use of the maximum of both, see Eq. 3. The aging factor is calculated in daily basis.

Typically a $20 \%$ reduction of the initial capacity is applied to define the end of life (EoL) of a battery [17], especially for industrial application since under this value the manufacturers do not guarantee the battery performance. However, lower values are often stated for residential applications which are less demanding [18, 19], in this study we use a 30\% capacity depletion as EoL.

Calendar losses have been previously modeled using the Arrhenius formula since they are mainly dependent on the battery temperature [19]. However, the temperature is controlled by the battery management system in new models available in the market. Therefore, the proposed model neglects its effect on the battery aging. Eq. 4 defines daily calendar aging $\left(\mathrm{cal}_{d}\right)$ as the multiplicative inverse of the battery calendar lifetime $\left(\right.$ Batt $\left._{\text {cal-life }}\right)$.

As for the cyclic aging $\left(c y c_{d}\right)$, we use a similar approach as the presented by Magnor et al. [17] which is based on Woehler curvesf for different battery technologies. We extend this method to other technologies adapting the maximum number of cycles performed by the battery. The cyclic aging is then given by 1 (i.e. the number of cycles per day at the given DoD), divided by the maximum number of cycles at the given $\operatorname{DoD}\left(N_{\max }^{D o D^{\star}}\right)$, as indicated by Eqs. 5 and 6. Since the energy discharged from the battery in one day can exceed the nominal capacity (e.g., if the battery is fully charged and discharged two times in a day), the cycling aging is considered to be the sum of one cycle at $100 \%$ DoD and one cycle at the remaining DoD.

$$
\begin{gathered}
\operatorname{aging}_{d}=\max \left(\text { cyc }_{d}, \text { cal }_{d}\right) \\
c a l_{d}=\frac{1}{\text { Batt }} \text { cal-life } \\
D o D^{\star}=\frac{\sum_{i=1}^{t} E_{d i s_{i}}}{C}
\end{gathered}
$$

\footnotetext{
${ }^{\mathrm{f}}$ The Woehler curves show the number of cycles of a battery as a function of depth of discharge until the end of lifetime. This curve is given by most battery manufacturers in data sheets.
} 


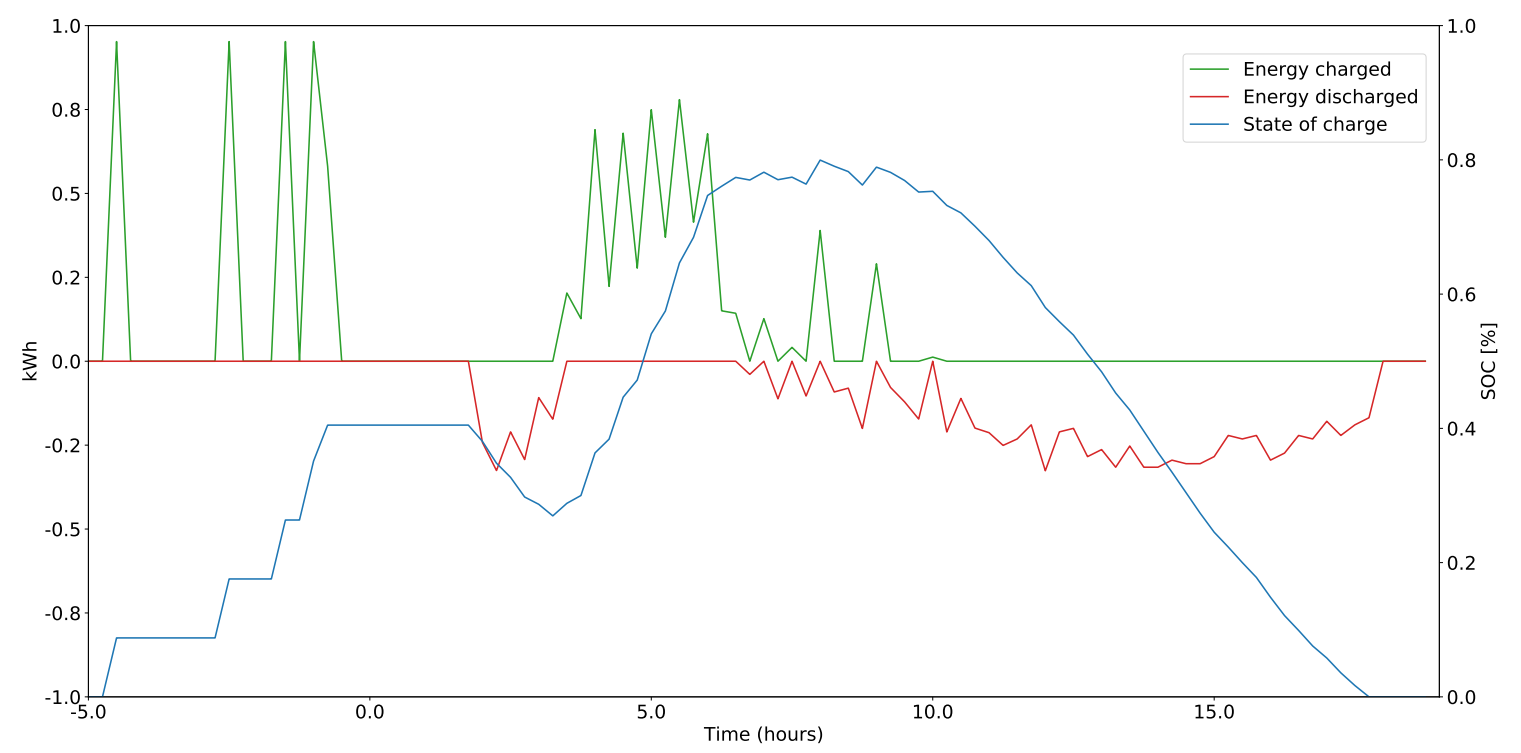

Fig. 8: Example of the battery scheduling in a typical day.

$$
c y c_{d}=\frac{1}{N_{\max }^{D o D^{\star}}}
$$

As an example, let us consider the battery scheduling presented in Fig. 8, which is the result of a given day for a $14 \mathrm{kWh}$ NMC-based battery. The total energy discharged in the given day is $9.88 \mathrm{kWh}$, thus the given $\mathrm{DoD}\left(\right.$ i.e., $D o D^{\star}$ ) is found dividing the total energy discharged by the total battery capacity, that is, 0.706 . We proceed to use the corresponding equation from Table 2, for the NMC technology, and it is found that at $D o D^{\star}$, the number of cycles at $0.706 \mathrm{DoD}$ is 4062.7 , thus, the cycling aging will be the inverse multiplicative, that is 0.000246 .

The Woehler curves used in this study are displayed in Fig. 9 and the equation that mathematically describes every curve is presented in Table2. Each curve is based on manufacturers' datasheets. 


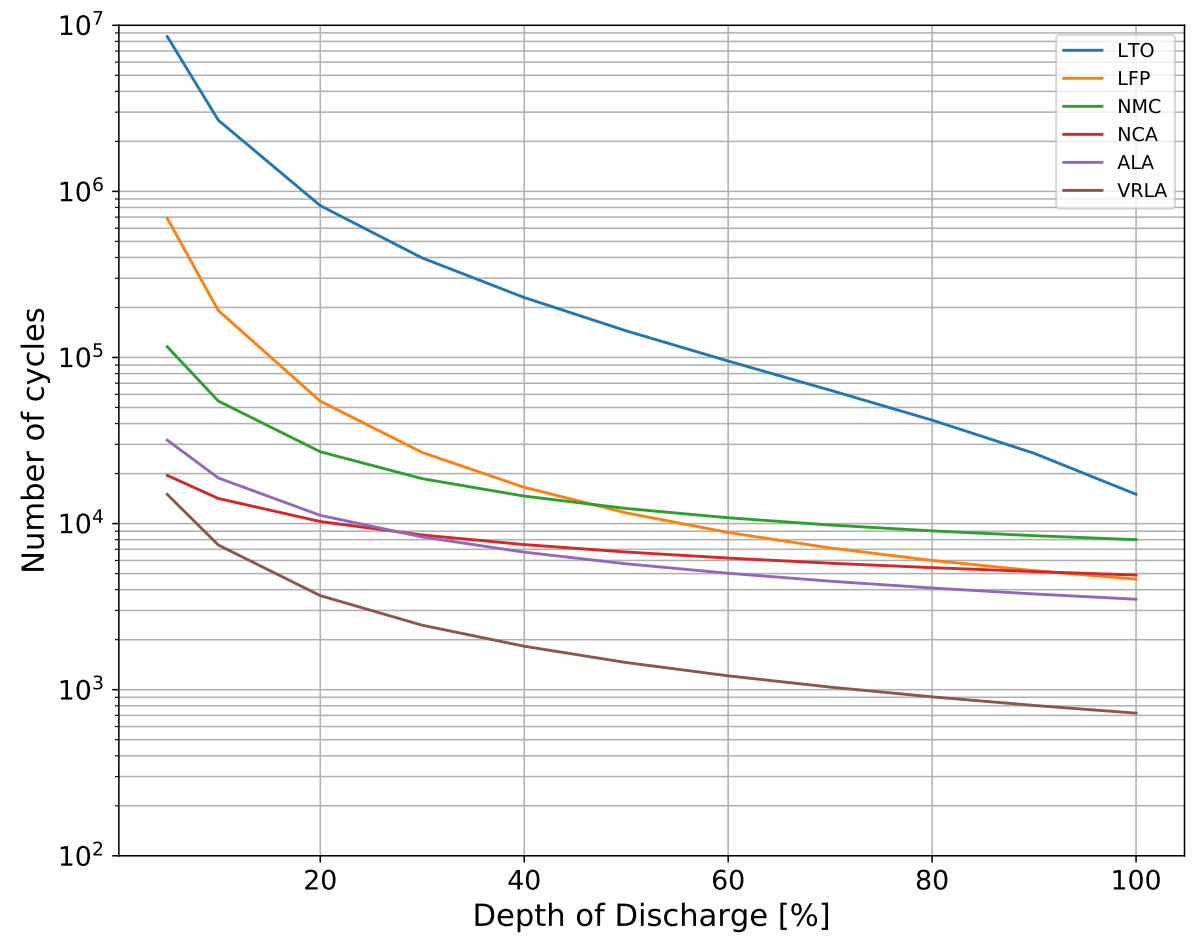

Fig. 9: Woehler curves for every technology used in this study.

\begin{tabular}{ccc}
\hline Technology & Number of cycles as a function of DoD & Reference \\
\hline LTO & $\exp \left(\frac{\log (D o D)-\log (771.51)}{-0.604}\right)-45300$ & {$[20]$} \\
LFP & $\exp \left(\frac{\log (D o D)-\log (70.869)}{-0.54}\right)+1961.37135$ & {$[21]$} \\
NCA & $\exp \left(\frac{\log (D o D)-\log (1216.7)}{-0.869}\right)+4449.67011$ & {$[22]$} \\
NMC & $\exp \left(\frac{\log (D o D)-\log (1 E 8)}{-2.168}\right)$ \\
ALA & $\exp \left(\frac{\log (D o D)-\log (37403)}{-1.306}\right)+330.656417$ & {$[24]$} \\
VRLA & $\exp \left(\frac{\log (D o D)-\log (667.61)}{-0.988}\right)$ & {$[25]$} \\
\hline
\end{tabular}

Table 2: Number of cycles for every technology used in this study. 


\section{Model validation}

In order to validate the model, some test scenarios with intuitive solutions for the optimum schedule of operation of the battery are considered. The three scenarios are run with a LFP battery with a large capacity (100 MWh) and efficiency of 100\%. The demand is considered to be constant at $100 \mathrm{~kW}$.

In the first case, presented in figure 10, the time-series test price presents a single time slot with a low price of $10 \mathrm{USD} / \mathrm{kWh}$ and a peak price of $100 \mathrm{USD} / \mathrm{kWh}$. The battery charging and discharging limits are set at $2^{*} \mathrm{C}$. The output is as expected a schedule where the battery is charged in the low-price time slot and discharged afterwards.

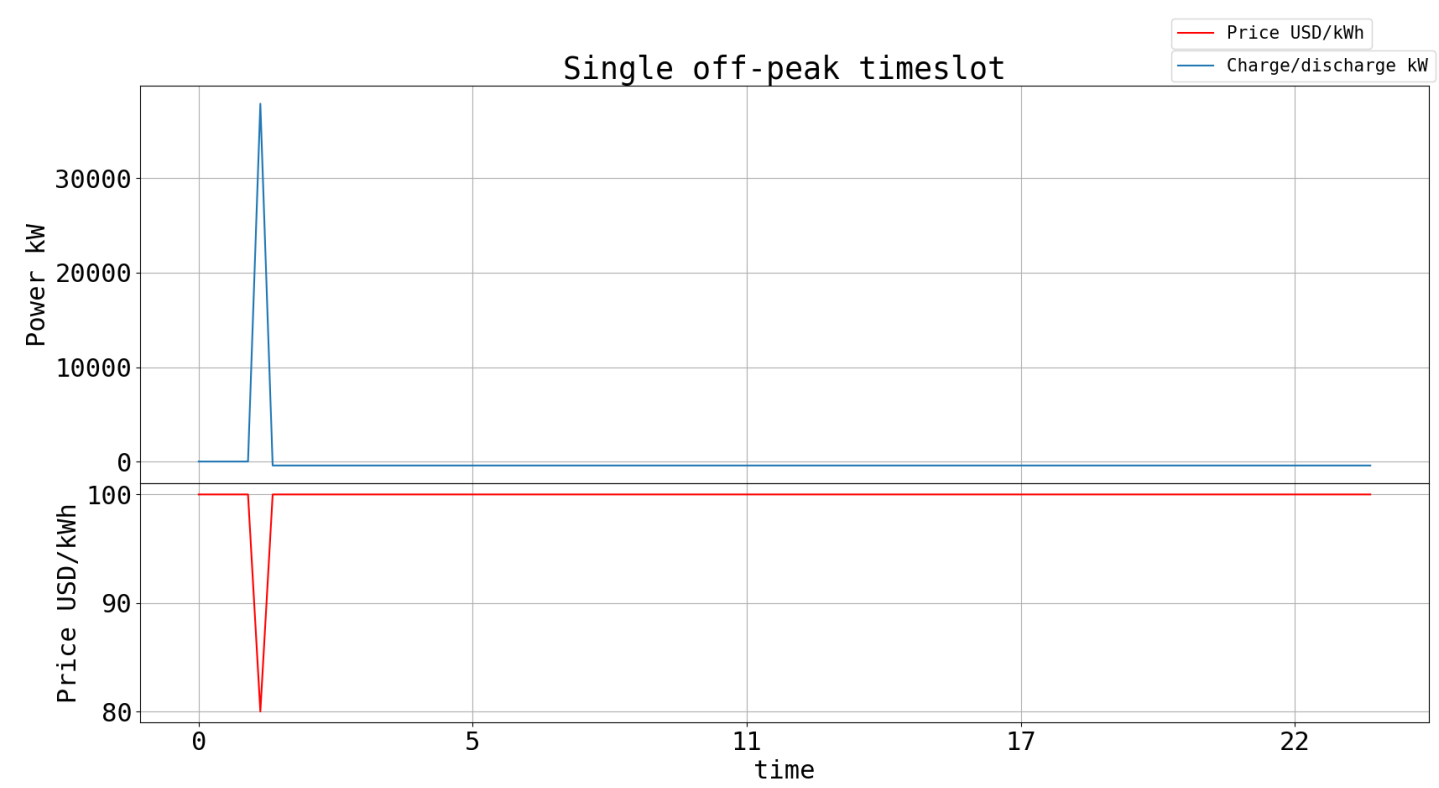

Fig. 10: Result for optimization of the single off-peak time slot test case. The output schedule for charge (positive y-axis) and discharge of the battery with the given price input.

In the second test, shown in figure 11 the time-series test price is a square wave varying between $100 \mathrm{USD} / \mathrm{kWh}$ and $10 \mathrm{USD} / \mathrm{kWh}$. The battery charging and discharging limits are set at $100 \mathrm{~kW}$. Therefore, we would expect the optimized result to output a schedule that charged when the prices are low, then discharged to cover the demand when the prices are high. The figure of the model results is an excellent fit with the expected schedule. A positive power flow means the battery is charging.

In the last test, shown in figure 12 the time-series test price is a sinus wave varying between $50 \mathrm{USD} / \mathrm{kWh}$ and $-50 \mathrm{USD} / \mathrm{kWh}$. The battery charging and discharging limits are set at $100 \mathrm{~kW}$. Therefore, we would expect the optimized result to output a schedule that charged when the prices are lower than $0 \mathrm{USD} / \mathrm{kWh}$, then discharged to cover the demand when the prices are high. We can see how at the end of the day, the battery charges only when prices are strictly below $0 \mathrm{USD} / \mathrm{kWh}$, since the battery does not charge if it does not need the energy before the end of the day. 


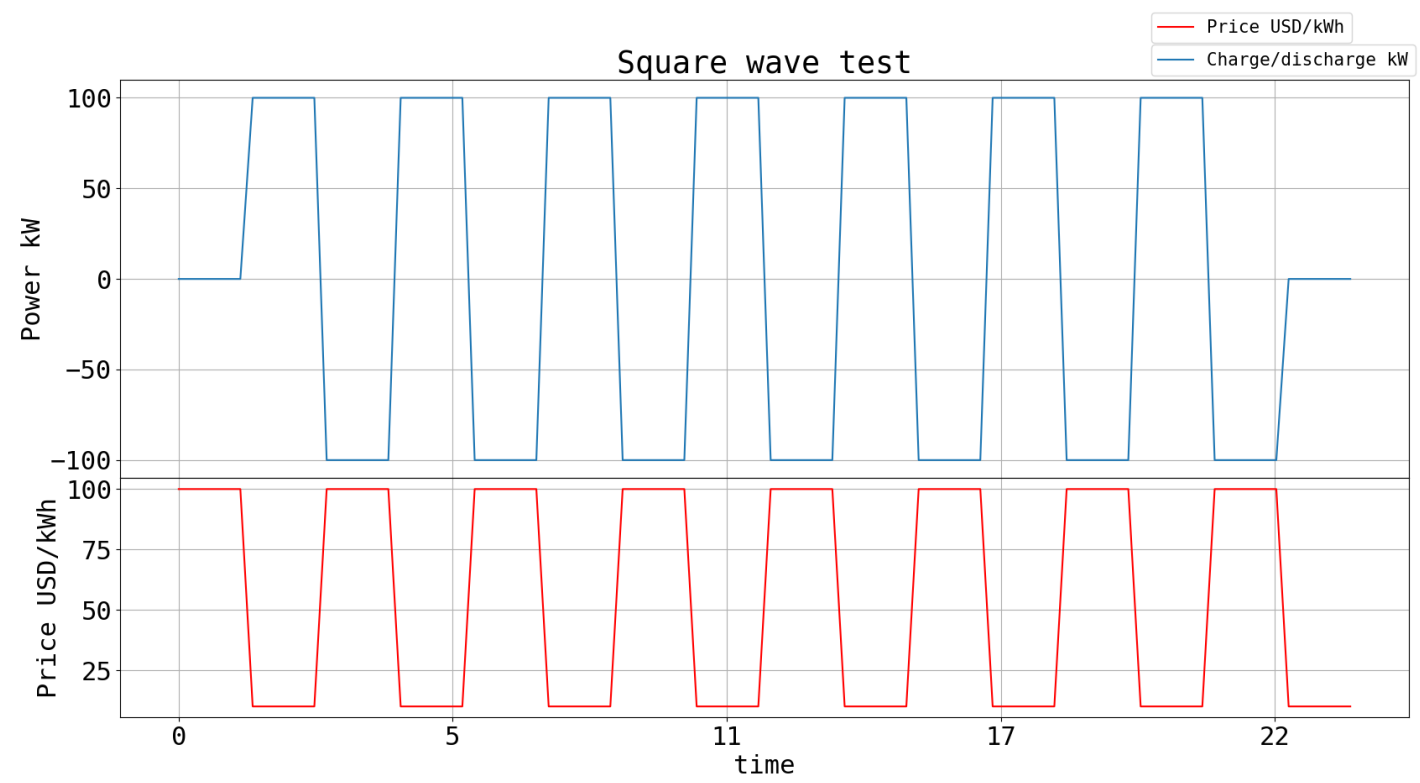

Fig. 11: Result for optimization of the square wave price test case. The output schedule for charge (positive $\mathrm{y}$-axis) and discharge of the battery with the given price input.

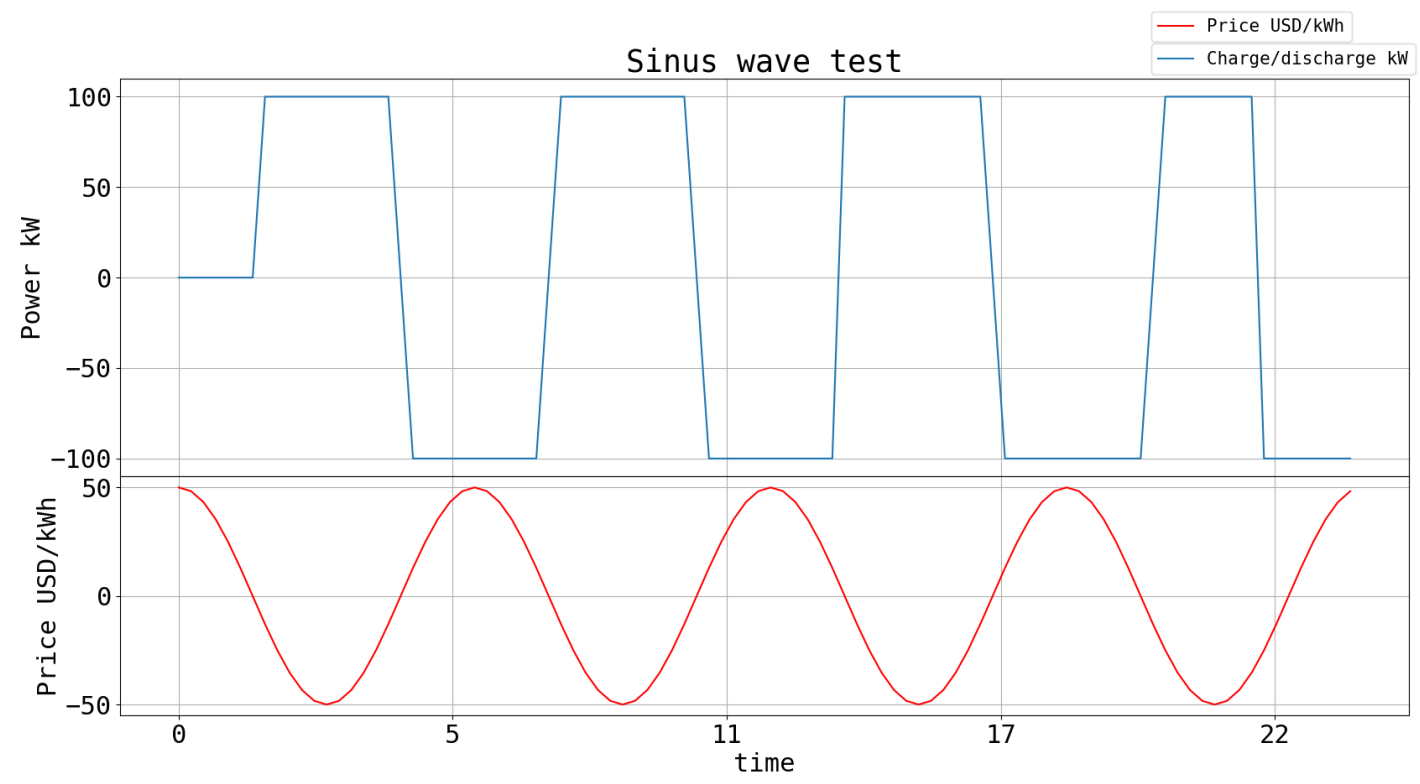

Fig. 12: Result for optimization of the sinus wave price test case. The output schedule for charge (positive $\mathrm{y}$-axis) and discharge of the battery with the given price input. 


\section{Other combinations of applications}

Results are presented here for a typical size of $7 \mathrm{kWh}$ depending on the battery technology and for both locations. Since we aim to analyze the impact of geography, battery technology and size on the attractiveness of the combination of applications, our baseline results are based on a representative (median) fixed PV size in each geographical region. Three additional combinations of applications are analyzed besides the five presented in the main paper. In order to give the reader a point of comparison, PV self-consumption only and the full combination of applications are as well deployed.

The main result drawn from Figs. 1314 and 15 is the influence of demand load shifting when combined with PV self-consumption and demand peak shaving, which helps to reduce the levelized cost and slightly enhance the added value. At the end it results in an improved NPV which is significantly higher than the scenario where avoidance of PV curtailment is combined with the same two applications.

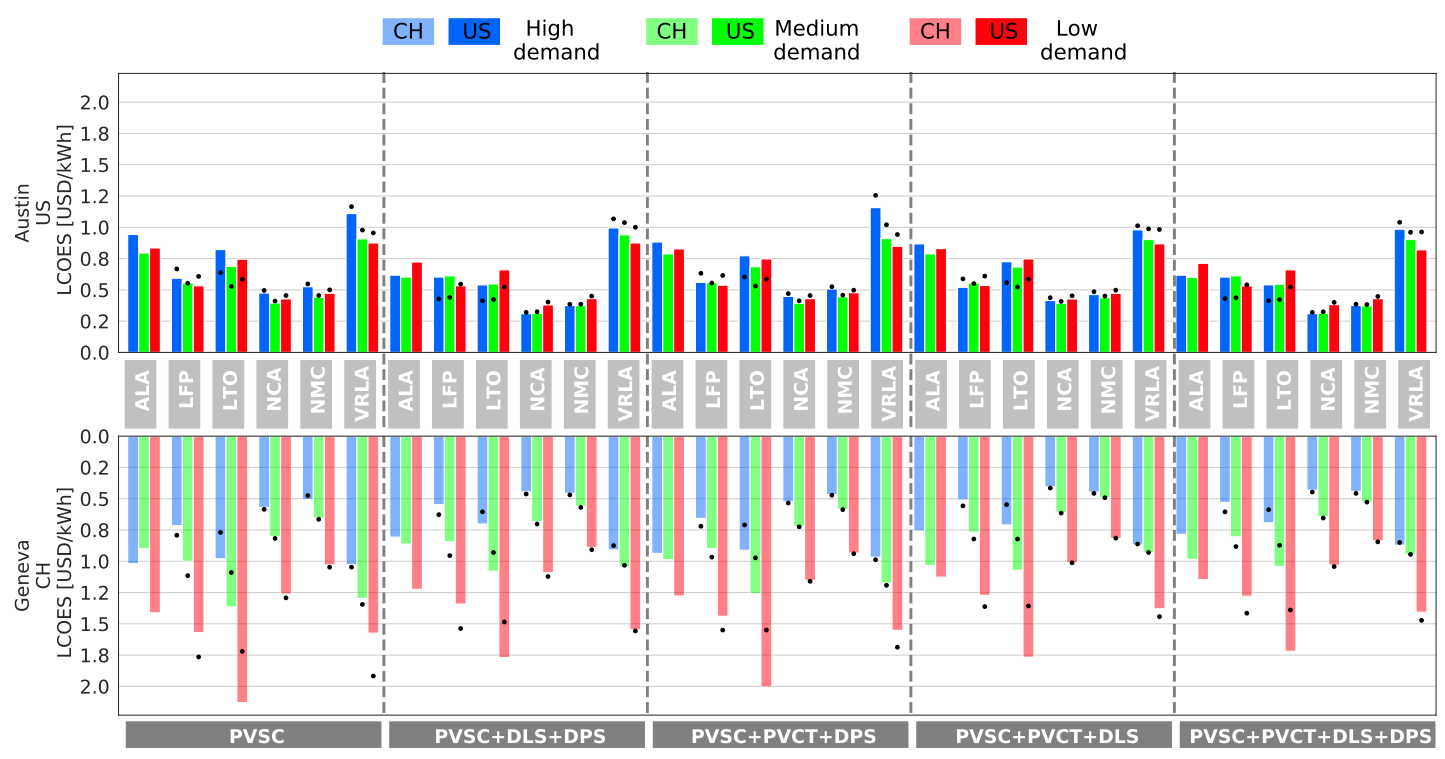

Fig. 13: Levelized cost of energy storage of a $7 \mathrm{kWh}$ battery for all battery technologies depending on the type of combination of applications for the U.S. (top) and Switzerland (bottom). The size the PV system correspond to the medium installed capacity across both locations. 


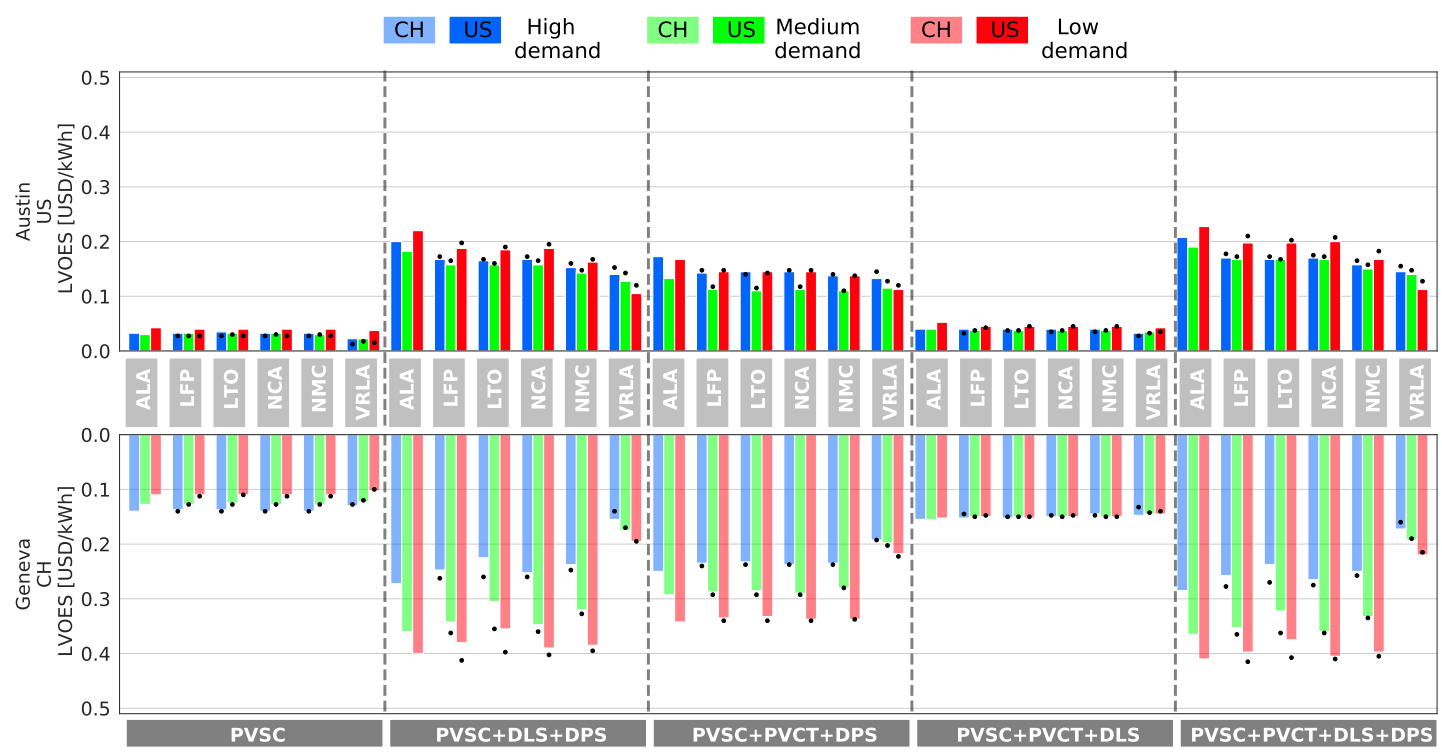

Fig. 14: Levelized value of energy storage of a $7 \mathrm{kWh}$ battery for all battery technologies depending on the type of combination of applications for the U.S. (top) and Switzerland (bottom). The size the PV system correspond to the medium installed capacity across both locations.

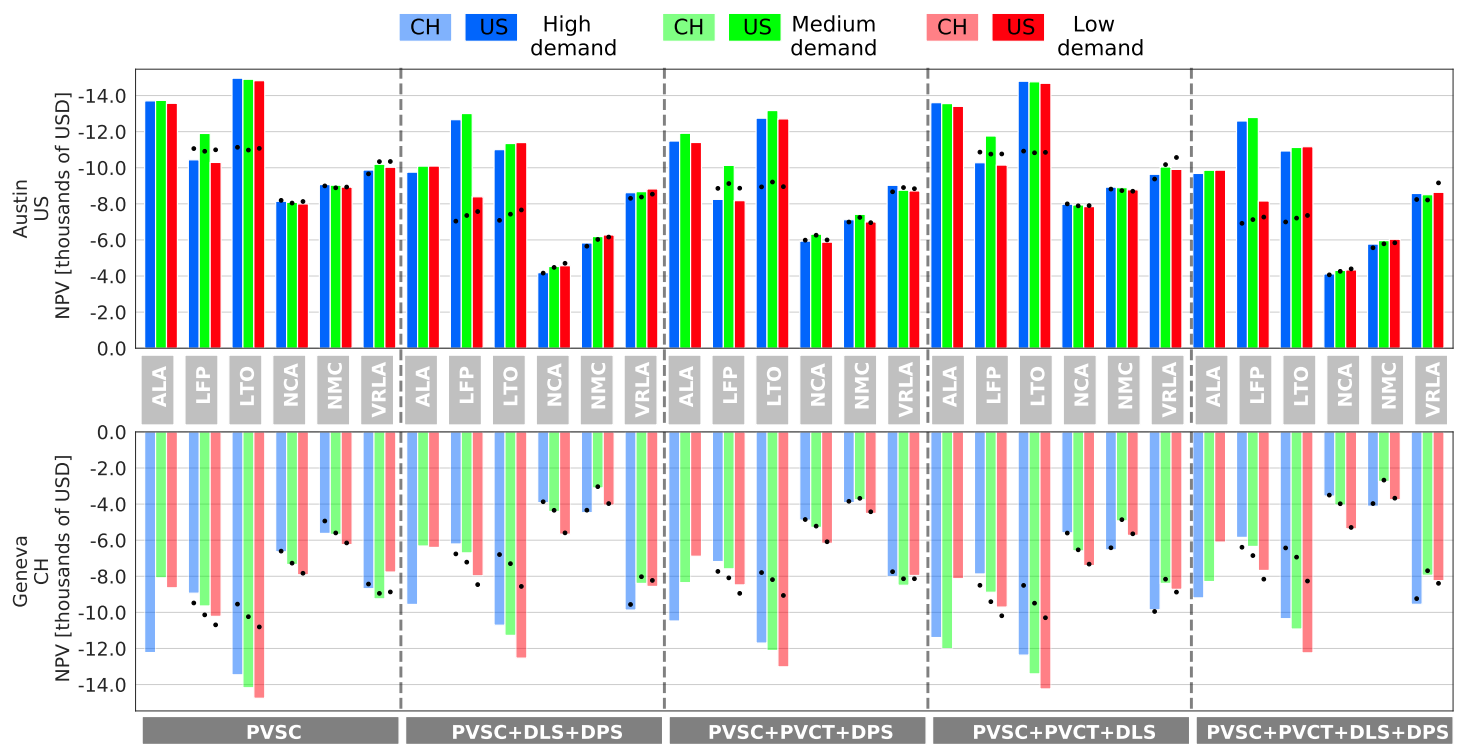

Fig. 15: Net present value of energy storage of a $7 \mathrm{kWh}$ battery for all battery technologies depending on the type of combination of applications for the U.S. (top) and Switzerland (bottom). The size the PV system correspond to the medium installed capacity across both locations. 


\section{PV size impact}

Fig. 16 displays the average LCOES, LVOES and NPV across the three groups of consumers, for the 25th, median and 75th quartiles of the PV size distribution for Switzerland and Fig 17 for the U.S., for a $7 \mathrm{kWh}$ battery performing simultaneously all consumer applications depending on the battery technology.

In general, the combination of applications reaches smaller levelized cost, higher levelized value and higher NPV for all batteries, with the exception of LFP-based batteries in the U.S. when median PV size is assessed (due to replacement near the end of life). Moreover, the difference between a battery performing PV self-consumption only and one performing all the applications simultaneously is higher as the PV size raises for the levelized value and the NPV, as for the levelized cost the difference diminishes with PV size.

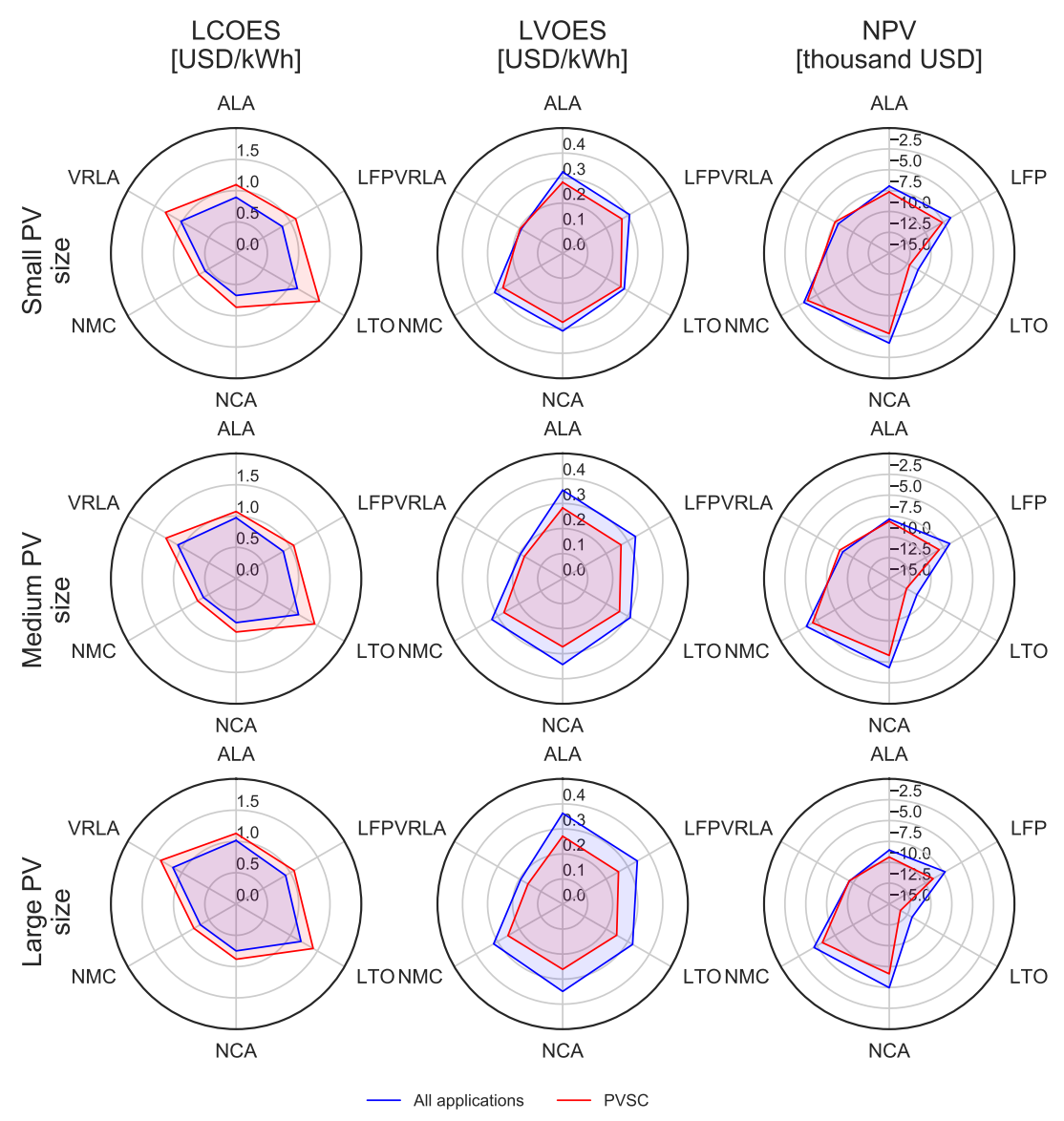

Fig. 16: Comparison of the average LCOES (left), LVOES (middle) and NPV (right) for various battery technologies and a $7 \mathrm{kWh}$ battery performing only PV self-consumption (red) and all consumer applications simultaneously (blue) in Switzerland, depending on the size of PV, namely small (top), medium (middle) and large (bottom). 


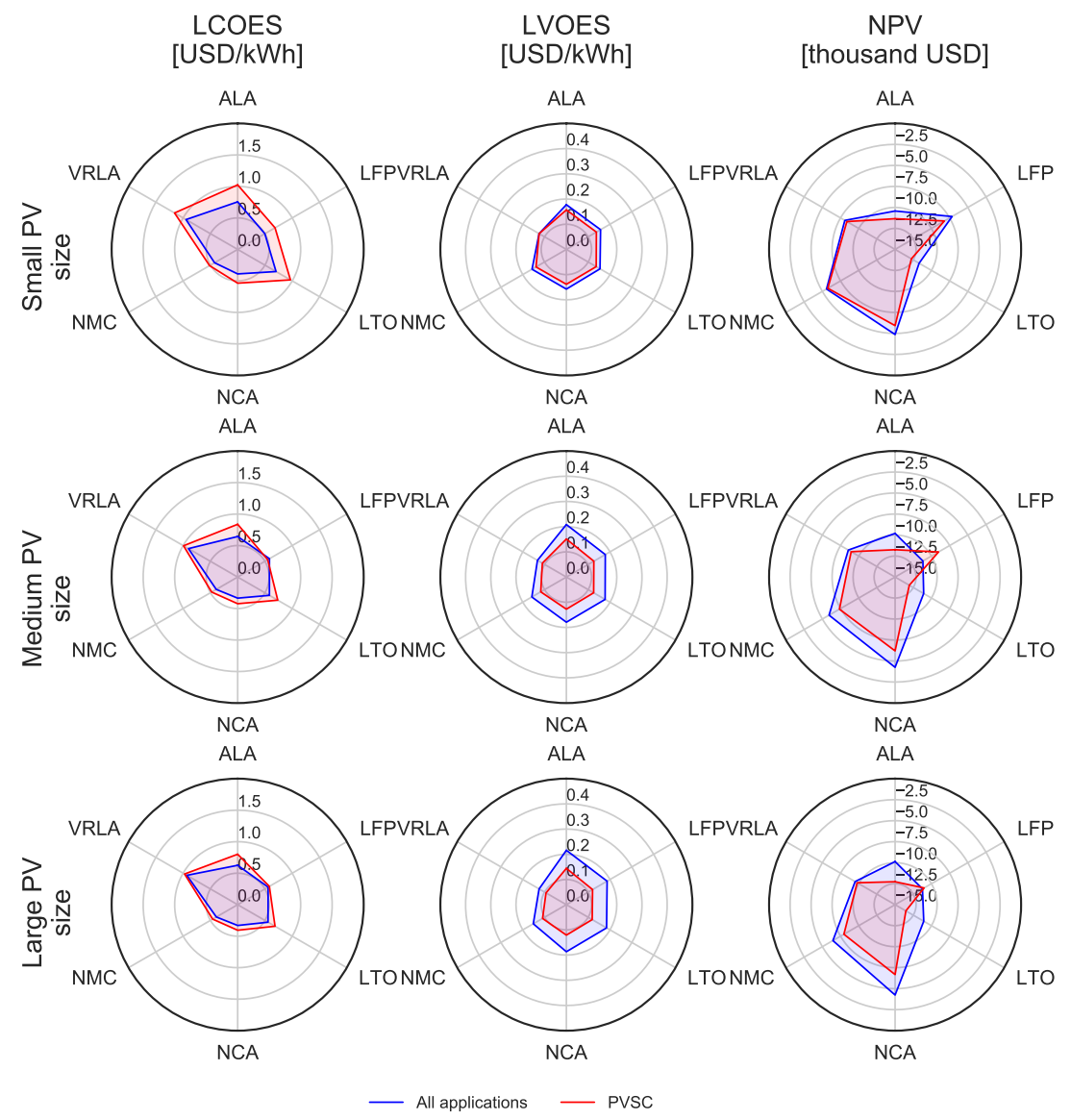

Fig. 17: Comparison of the average LCOES (left), LVOES (middle) and NPV (right) for various battery technologies and a $7 \mathrm{kWh}$ battery performing only PV self-consumption (red) and all consumer applications simultaneously (blue) in the U.S., depending on the size of PV, namely small (top), medium (middle) and large (bottom). 


\section{References}

[1] Chicco G. Overview and performance assessment of the clustering methods for electrical load pattern grouping. Energy. 2012;42(1):68-80. https://doi.org/10.1016/ j.energy.2011.12.031.

[2] Kwac J, Flora J, Rajagopal R. Household energy consumption segmentation using hourly data. IEEE Trans Smart Grid. 2014;5(1):420-430. https://doi.org/10.1109/ TSG.2013.2278477.

[3] Xu S, Barbour E, González MC. Household segmentation by load shape and daily consumption. In: Proc. 6th ACM SIGKDD Int. Worksh. Urban Computing Conf. Halifax, Nov. Scotia, Canada, August 2017. vol. 2; 2017. [Accessed on 27/05/2019] http://urbcomp.ist.psu.edu/2017/papers/Household.pdf.

[4] Benítez I, Quijano A, Díez JL, Delgado I. Dynamic clustering segmentation applied to load profiles of energy consumption from Spanish customers. Int $\mathrm{J}$ Elec Power. 2014;55:437-448. https://doi.org/10.1016/j.ijepes.2013.09.022.

[5] Al-Wakeel A, Wu J, Jenkins N. K-means based load estimation of domestic smart meter measurements. Appl Energy. 2017;194:333-342. https://doi.org/10.1016/ j.apenergy.2016.06.046.

[6] HIT photovoltaic module HIT-N2XXSE10 datasheet;. [Accessed on 27/05/2019] https: //www.evoenergy.co.uk/wp-content/uploads/2012/09/Datasheet-HIT-250W.pdf.

[7] Pfenninger S, Staffell I. Long-term patterns of European PV output using 30 years of validated hourly reanalysis and satellite data. Energy. 2016;114:1251-1265. https: //doi.org/10.1016/j.energy.2016.08.060.

[8] Fu R, Feldman DJ, Margolis RM, Woodhouse MA, Ardani KB. US solar photovoltaic system cost benchmark: Q1 2017. Golden, CO: National Renewable Energy Laboratory (NREL). NREL/TP-6A20-68925; (2017). [Accessed on 27/05/2019] https://www.nrel.gov/docs/fy17osti/68925.pdf.

[9] Pius Husser. National Survey Report of PV Power Applications in Switzerland 2016. Nova Energie GmbH / IEA PVPS; 2017. [Accessed on 27/05/2019] http: //iea-pvps.org/index.php?id=93\&eID=dam_frontend_push\&docID=4055.

[10] Lim CS, Yurukoglu A. Dynamic Natural Monopoly Regulation: Time Inconsistency, Moral Hazard, and Political Environments. J Political Econ. 2018;126(1):263-312. https://doi.org/10.1086/695474.

[11] Burger B, Rüther R. Inverter sizing of grid-connected photovoltaic systems in the light of local solar resource distribution characteristics and temperature. Solar Energy. 2006;80(1):32-45. https://doi.org/10.1016/j.solener.2005.08.012. 
[12] Bundestag Deutscher. Gesetz für den Ausbau erneuerbarer Energien. ErneuerbareEnergien-Gesetz(EEG 2017); 2017. [Accessed on 27/05/2019] https://www.gesetzeim-internet.de/eeg_2014/.

[13] KfW Bank. Förderprogram Erneuerbare Energien-Speicher. KfW Bank; 2016. [Accessed on 27/05/2019] https://www.kfw.de/inlandsfoerderung/Unternehmen/EnergieUmwelt/F\%C3\%B6rderprodukte/Erneuerbare-Energien-\%E2\%80\%93-Speicher$(275) /$.

[14] VictronEnergy. EasySolar 12/1600/70; 2017. [Accessed on 27/05/2019] https:// WWW.victronenergy.no/upload/documents/Datasheet-EasySolar-1600VA-EN.pdf.

[15] Schmidt T, Beuse M, Xiaojin Z, Steffen B, Schneider S, Pena-Bello A, et al. Additional emissions and cost from storing electricity in stationary battery systems. Environ Sci Technol. 2019;53(7):3379-3390. https://doi.org/10.1021/acs.est.8b05313.

[16] Hesse HC, Schimpe M, Kucevic D, Jossen A. Lithium-Ion Battery Storage for the Grid?A Review of Stationary Battery Storage System Design Tailored for Applications in Modern Power Grids. Energies. 2017;10(12):2107. https://doi.org/10.3390/en10122107.

[17] Sauer DU, Merk P, Ecker M, Gerschler JB, Magnor D. Concept of a Battery Aging Model for Lithium-Ion Batteries Considering the Lifetime Dependency on the Operation Strategy. In: 24th European Photovoltaic Solar Energy Conference, 21-25 September, Hamburg, Germany; 2009. p. 3128-3134. https://doi.org/10.4229/24thEUPVSEC20094B0.11.3.

[18] Hesse HC, Martins R, Musilek P, Naumann M, Truong CN, Jossen A. Economic Optimization of Component Sizing for Residential Battery Storage Systems. Energies. 2017;10. https://doi.org/10.3390/en10070835.

[19] Käbitz S, Gerschler JB, Ecker M, Yurdagel Y, Emmermacher B, André D, et al. Cycle and calendar life study of a graphite - LiNi1/3Mn1/3Co1/3O2 Li-ion high energy system. Part A: Full cell characterization. J Power Sources. 2013;239:572-583. https://doi.org/10.1016/j.jpowsour.2013.03.045.

[20] XALT 60Ah High Power Lithium-Ion LTO Cell; 2018. [Accessed on 27/05/2019] https : //www.xaltenergy.com/wp-content/uploads/2018/08/60Ah-LTO.pdf.

[21] Omar N, Monem MA, Firouz Y, Salminen J, Smekens J, Hegazy O, et al. Lithium iron phosphate based battery ? Assessment of the aging parameters and development of cycle life model. Appl Energy. 2014;113:1575 - 1585. https://doi.org/10.1016/ j.apenergy.2013.09.003.

[22] Trina BESS. S Series NCA type battery; 2017. [Accessed on 27/05/2019] http:// wWw.trinaenergystorage.com/uploads/download/149560986943.pdf.

[23] Truong CN, Naumann M, Karl RCK, Müller M, Jossen A, Hesse HC. Economics of Residential Photovoltaic Battery Systems in Germany: The Case of Tesla's Powerwall. Batteries. 2016;2(2):14. https://doi.org/10.3390/batteries2020014. 
[24] FCP-1000 Lead Carbon Battery; 2018. [Accessed on 27/05/2019] https://resenergy.at/files/res-fcp-1000.pdf.

[25] Sonnenschein. Handbook for Gel-VRLA-Batteries; 2013. [Accessed on 27/05/2019] http://www.sonnenschein.org/PDF\%20files/GelHandbookPart2.pdf. 